\title{
Formation of NO and N2O during Raw and Demineralized Biomass Char Combustion
}

\author{
Ulusoy, Burak; Lin, Weigang; Karlstrom, Oskar; Li, Songgeng; Song, Wenli; Glarborg, Peter; Dam- \\ Johansen, Kim; Wu, Hao
}

\section{Published in:}

Energy and Fuels

Link to article, DOI:

10.1021/acs.energyfuels.9b00622

Publication date:

2019

Document Version

Peer reviewed version

Link back to DTU Orbit

Citation (APA):

Ulusoy, B., Lin, W., Karlstrom, O., Li, S., Song, W., Glarborg, P., Dam-Johansen, K., \& Wu, H. (2019). Formation of $\mathrm{NO}$ and $\mathrm{N} O$ during Raw and Demineralized Biomass Char Combustion. Energy and Fuels, 33(6), 53045315. https://doi.org/10.1021/acs.energyfuels.9b00622

\section{General rights}

Copyright and moral rights for the publications made accessible in the public portal are retained by the authors and/or other copyright owners and it is a condition of accessing publications that users recognise and abide by the legal requirements associated with these rights.

- Users may download and print one copy of any publication from the public portal for the purpose of private study or research.

- You may not further distribute the material or use it for any profit-making activity or commercial gain

- You may freely distribute the URL identifying the publication in the public portal 


\title{
Formation of $\mathrm{NO}$ and $\mathrm{N}_{2} \mathrm{O}$ during raw and
}

\section{demineralized biomass char combustion}

\author{
Burak Ulusoy 1,2,3, Weigang Lin 1,3, Oskar Karlström ${ }^{4}$, Songgeng Li ${ }^{3,5}$, Wenli Song ${ }^{3,5}$, \\ Peter Glarborg ${ }^{1}$, Kim Dam-Johansen ${ }^{1}$, Hao $\mathrm{Wu}^{{ }^{1 *}}$ \\ 1: Department of Chemical and Biochemical Engineering, Technical University of Denmark, \\ Søltofts Plads 229, 2800 Kgs. Lyngby, Denmark \\ 2: Sino-Danish Centre for Education and Research, Beijing, China \\ 3: Sino-Danish College, University of Chinese Academy of Sciences, Beijing 100049, China \\ 4: Johan Gadolin Process Chemistry Centre, Åbo Akademi University, Finland \\ 5: State Key Laboratory of Multiphase Complex Systems, Institute of Process Engineering, \\ Chinese Academy of Sciences, Beijing 100190, China
}

Keywords: Biomass, char, nitrogen oxides, $\mathrm{NO}, \mathrm{N}_{2} \mathrm{O}$, char nitrogen conversion, $\mathrm{NO}$ reduction

*Corresponding author e-mail id: haw@,kt.dtu.dk

Most recent modification date: 29-Apr-19 
1 Abstract: The formation of nitrogen oxides $\left(\mathrm{NO}\right.$ and $\left.\mathrm{N}_{2} \mathrm{O}\right)$ during raw and demineralized biomass

2 char combustion and the reduction of $\mathrm{NO}$ over biomass char were investigated. The biomass fuels

3 were pine wood, straw, waste wood, bran, dried distillers grains with solubles (DDGS), and

4 sunflower seed. Fixed bed combustion experiments were performed at $800^{\circ} \mathrm{C}$ in $10 \mathrm{vol} \% \mathrm{O}_{2}$, while

$5 \mathrm{NO}$ reduction experiments were conducted at temperatures from 800 to $900^{\circ} \mathrm{C}$ and $\mathrm{NO}$ inlet

6 concentrations from 400 to 1500 ppmv. The chars were characterized by means of ICP-OES, BET,

7 SEM-EDX, and XPS. The conversion of char-N to NO decreased with an increase in the initial

8 char- $\mathrm{N}$ content, partly explained by the increased inherent conversion of char- $\mathrm{N}$ to $\mathrm{N}_{2} \mathrm{O}$. The

9 reduction of $\mathrm{NO}$ over char exhibited no correlation to the surface functionalities and content of

10 nitrogen and oxygen at the investigated conditions. The NO reduction reactivity was strongly

11 dominated by the content and association of ash forming elements in the chars. The NO reduction

12 reactivity of pine wood, waste wood, and straw chars correlated reasonably well with the $(\mathrm{K}+\mathrm{Ca}) / \mathrm{C}$

13 molar ratio, while the chars with a high phosphorous content, i.e., bran, DDGS, and sunflower

14 seed chars, differed by showing a significantly lower reactivity. The inhibition effect of

15 phosphorous on NO reduction reactivity was likely caused by the formation of less catalytically

16 active potassium species (such as $\mathrm{KPO}_{3}$ ) in biomass char. 


\section{Introduction}

18 Minimizing nitrogen oxides $\left(\mathrm{NO}_{\mathrm{X}}\right)$ emissions from industrial solid fuel combustion is important 19 due to the harmful environmental impact and strict emission regulations. In fluidized bed 20 combustion $(\mathrm{FBC}), \mathrm{NO}_{\mathrm{X}}$ primarily stems from the fuel bound nitrogen through volatile and char 21 oxidation. While the gaseous nitrogen chemistry is fairly well established, ${ }^{1,2}$ the conversion of 22 char-N to NO is less understood, especially in the case of high-nitrogen biomass fuels. During char 23 combustion, $\mathrm{NO}$ is simultaneously formed from and reduced by char. The final emission of $\mathrm{NO}_{\mathrm{X}}$ 24 is determined by the competing $\mathrm{NO}_{\mathrm{X}}$ formation and reduction reactions. ${ }^{3}$

25 The products of char nitrogen combustion include primarily $\mathrm{NO}, \mathrm{N}_{2} \mathrm{O}$, and $\mathrm{N}_{2}{ }^{4}$ During fixed 26 bed coal char combustion at single particle conditions, the conversion of char-N to NO ranged 27 from $75-100 \%{ }^{4,5}$ Similar experiments employing biomass chars yielded char-N to NO conversions 28 in a range of $25-75 \%$, implying a significant reduction of NO during biomass char combustion. ${ }^{6}$

29 The fractional conversion of char-N depends on the operating conditions (such as temperature and 30 gas composition) and the fuel properties. ${ }^{4}$

31 The proposed mechanism for the formation and reduction of NO during char combustion in an $32 \mathrm{O}_{2} / \mathrm{N}_{2}$ system is summarized in R1-R2 and R3-R9, repectively. ${ }^{7-11}$ Here, (-CX) denotes a carbon 33 surface complex of either nitrogen or oxygen, while (-C) is a free carbon active site and $\mathrm{M}$ is a 34 catalytically active ash forming element. The dissociative chemisorption of NO occurs in R3 and $35 \mathrm{R} 7$ followed by reduction through $\mathrm{R} 4$ and $\mathrm{R} 5$, and active site regeneration by R8 and R9. 36 Additionally, the presence of $\mathrm{CO}$ has been reported to enhance the reduction reaction, ${ }^{12}$ 37 presumably by reaction with NO catalyzed by char, demonstrated by the non-elementary R6. 38 Ultimately, the (-CO) is released to the gas phase as $\mathrm{CO}$ or $\mathrm{CO}_{2}$, and a free active site is formed. 39 Several reviews dealing with the reduction reaction between NO and coal char have been 
40 reported. ${ }^{3,4,13-15}$ Compared to coal, biomass chars generally exhibit a higher reactivity towards NO

41 reduction. ${ }^{8,12,16}$ This has been attributed the higher potassium content and larger surface area of

42 biomass chars. Besides these, other factors such as increased amounts of sodium ${ }^{17}$, magnesium ${ }^{18}$,

43 calcium, and iron ${ }^{19}$, and more effective porosity ${ }^{20}$ have been shown to enhance the NO reduction

44 reactivity.

$$
\begin{array}{rll}
\mathrm{O}_{2}+(-\mathrm{C})+(-\mathrm{CN}) & \rightarrow(-\mathrm{CO})+(-\mathrm{CNO}) & \mathrm{R} 1 \\
(-\mathrm{CNO}) & \rightarrow \mathrm{NO}+(-\mathrm{C}) & \mathrm{R} 2 \\
\mathrm{NO}+2(-\mathrm{C}) & \rightarrow(-\mathrm{CO})+(-\mathrm{CN}) & \mathrm{R} 3 \\
2(-\mathrm{CN}) & \rightarrow \mathrm{N}_{2}+2(-\mathrm{C}) & \mathrm{R} 4 \\
(-\mathrm{CN})+\mathrm{NO} & \rightarrow \mathrm{N}_{2}+(-\mathrm{CO}) & \mathrm{R} 5 \\
2 \mathrm{NO}+2 \mathrm{CO} & \left.\rightarrow \mathrm{N}_{2}+2 \mathrm{CO}_{2} \quad \text { (over char }\right) & \mathrm{R} 6 \\
\left(-\mathrm{M}_{\mathrm{x}} \mathrm{O}_{\mathrm{y}}\right)+(-\mathrm{C})+\mathrm{NO} & \rightarrow\left(-\mathrm{M}_{\mathrm{x}} \mathrm{O}_{\mathrm{y}+1}\right)+(-\mathrm{CN}) & \mathrm{R} 7 \\
\left(-\mathrm{M}_{\mathrm{x}} \mathrm{O}_{\mathrm{y}+1}\right)+(-\mathrm{C}) & \rightarrow\left(-\mathrm{M}_{\mathrm{x}} \mathrm{O}_{\mathrm{y}}\right)+(-\mathrm{CO}) & \mathrm{R} 8 \\
(-\mathrm{CO}) & \rightarrow \mathrm{CO}+(-\mathrm{C}) & \mathrm{R} 9
\end{array}
$$

45 Studies have shown that the conversion of char-N to NO decreased with an increase in char-N

46 content and external NO concentration. ${ }^{8,21,22}$ This effect was more pronounced with demineralized

47 biomass, wherein the influence of the inorganics was minimized. ${ }^{8}$ These results indicate that the

48 formation and reduction of $\mathrm{NO}$ are related to the initial char-N content and gas phase NO

49 concentration. The reaction rate between char and NO was suggested to be proportionally

50 correlated to the instantaneous $\mathrm{NO}$ and $\mathrm{C}(\mathrm{N})$ concentrations. ${ }^{7} \mathrm{R} 3-\mathrm{R} 9$ are indicative that higher

51 contents of char-N and ash forming elements would lead to higher NO reduction rates.

52 Consequently, the reactivity of high-nitrogen chars towards NO could conceivably be enhanced

53 by the initial char-N content. In addition, although the influence of the ash forming elements on 
54 the char NO reactivity has been well documented ${ }^{8,12}$, the importance of their association in the raw 55 biomass is still unclear.

56 To obtain an improved understanding of the declining tendency in char-N conversion to NO 57 with an increase in char-N content, a thorough study of the NO formation and reduction during 58 raw and demineralized biomass char combustion was conducted in a fixed bed reactor at conditions 59 relevant to fluidized bed combustion. The product distribution from char- $\mathrm{N}$ oxidation was 60 characterized and its dependency on the chemical composition of the chars was investigated. The 61 NO reduction reactivity of the chars was examined at different temperatures and NO inlet 62 concentrations. The results were interpreted based on analyses of the surface area, char-N content, 63 nitrogen and oxygen surface functionality, and ash forming element content and association in 64 biomass chars. 


\section{Experimental Section}

$66 \quad$ Fuels and their demineralization

67 Six types of biomass, pine wood, straw, waste wood, bran, dried distillers grains with solubles

68 (DDGS), and sunflower seed, were employed in the experiments. Table 1 shows the composition

69 of selected elements in the raw fuels. The complete compositions are given in the supplemental

70 material (Table S1). The nitrogen contents ranged from 0.2 to $6.14 \mathrm{wt} \%$, thereby covering a wide

71 range of nitrogen contents in biomass fuels.

72 Table 1. Chemical composition of the six biomass.

\begin{tabular}{|c|c|c|c|c|c|c|c|c|c|c|c|c|}
\hline \multirow[b]{2}{*}{ Fuel } & \multicolumn{6}{|c|}{ [wt\% d.b] } & \multicolumn{6}{|c|}{ [mg/kg d.b.] } \\
\hline & $\mathbf{C}$ & $\mathbf{H}$ & $\mathbf{N}$ & $\mathbf{O}$ & $\mathbf{S}$ & Ash & $\mathbf{K}$ & $\mathbf{P}$ & Mg & $\mathbf{C a}$ & $\mathbf{F e}$ & $\mathbf{N a}$ \\
\hline Pine wood & 51.5 & 6.20 & $<0.20$ & 41.9 & 0.007 & 0.2 & 480 & 52 & 140 & 950 & 26 & 95 \\
\hline Straw & 46.9 & 6.00 & 0.56 & 42.2 & 0.120 & 4.2 & 14,000 & 910 & 960 & 2,300 & 41 & 230 \\
\hline Waste wood & 49.0 & 6.13 & 1.33 & 41.8 & 0.037 & 1.7 & 703 & 93 & 443 & 3,200 & 363 & 326 \\
\hline Bran & 45.0 & 6.30 & 2.65 & 40.6 & 0.19 & 5.3 & 13,000 & 11,000 & 3,800 & 920 & 210 & 50 \\
\hline Sunfl. seed & 40.5 & 5.73 & 6.14 & 33.4 & 0.23 & 14 & 18,416 & 12,810 & 6,724 & 7,328 & 1,730 & 410 \\
\hline DDGS & 43.7 & 6.55 & 5.13 & 37.8 & 0.41 & 6.4 & 11,723 & 10,204 & 3,442 & 1,105 & 91 & 3,255 \\
\hline
\end{tabular}

74 The biomass samples were demineralized (DM) following the work of Aho et al. ${ }^{23}$ Biomass was

75 initially ground and sieved to a size range of 212-1000 $\mu \mathrm{m}$ and subsequently suspended in $500 \mathrm{~mL}$

76 of $\mathrm{HNO}_{3}$ (Sigma Aldrich, CAS number: 7697-37-2) solution at pH 2 and heated to $60^{\circ} \mathrm{C}$. The

77 leaching was continued for one hour at $60^{\circ} \mathrm{C}$ under stirring at $750 \mathrm{rpm}$. After one hour, the solids

78 were collected by filtration and the leaching process repeated. Then, the biomass was filtered with

$79250 \mathrm{~mL}$ demineralized water until the permeate $\mathrm{pH}$ was above 6.0. The obtained demineralized

80 biomass was dried at $105^{\circ} \mathrm{C}$ for one day. 
81 A chemical fractionation method was used to separate the different groups of ash forming

82 elements in straw. ${ }^{24-27}$ To eliminate the influence of water-soluble materials such as alkali sulfates,

83 carbonates, chlorides, and to a lesser extent organically bound metals, 30-35 g of straw was washed

84 in $500 \mathrm{~mL}$ deionized water at room temperature under stirring at $750 \mathrm{rpm}$ for $24 \mathrm{~h}$. Subsequently,

85 the liquid was removed by filtration, and the extraction process repeated. After the second

86 leaching, the suspended solids were washed several times with $250 \mathrm{~mL}$ deionized water until the

87 permeate $\mathrm{pH}$ was above 6.0. Following this, half of the water washed (WW) straw was dried at

$88105^{\circ} \mathrm{C}$ for one day, while the other half was suspended in $150 \mathrm{~mL} 1 \mathrm{M}$ ammonium acetate (Fluka

89 Chemica, CAS number: 631-61-8) to remove ion-exchangeable cations in the form of organically

90 bound metals. The ammonium acetate treatment was continued for one day under stirring at 750

$91 \mathrm{rpm}$, after which the organic washed (OW) straw was washed using $100 \mathrm{~mL}, 1 \mathrm{M}$ ammonium

92 acetate for the first wash and $250 \mathrm{~mL}$ deionized water for the subsequent washes until the permeate

$93 \mathrm{pH}$ was above 6.0. The filtered solids were dried at $105^{\circ} \mathrm{C}$ for one day.

\section{$94 \quad$ Char preparation}

95 Chars from raw and DM biomass were prepared in a horizontal oven at $800^{\circ} \mathrm{C}$ using a $\mathrm{N}_{2}$ flow 96 of $2.5 \mathrm{NL} / \mathrm{min}$. The pyrolysis temperature was monitored through a thermocouple placed in the 97 middle of the oven. Upon reaching the desired temperature, approximately $10 \mathrm{~g}$ of biomass was 98 quickly pushed into the reactor. The pyrolysis was continued for 10 minutes, after which the 99 sample was rapidly withdrawn to a water cooled section to ensure prompt cooling. The char 100 samples were withdrawn from the reactor below a temperature of approximately $150^{\circ} \mathrm{C}$. The char 101 yield was determined from the biomass and char mass.

$102 \quad$ Experimental setup 
103 Figure 1 illustrates the quartz fixed bed reactor used for char combustion and NO reduction 104 experiments. ${ }^{10}$ The temperature in the bed was kept uniform by three independent heating elements 105 and monitored by a thermocouple located $0.5 \mathrm{~cm}$ below the porous plate. Upon reaching the 106 desired conditions, a solid feeding device enabled the introduction of a char-sand sample. In all 107 experiments, $1.75 \mathrm{~g}$ quartz sand with a size of $250-355 \mu \mathrm{m}$, pre-treated at $800^{\circ} \mathrm{C}$, was added 108 together with the char to facilitate sample admission and ensure a constant bed height. Blank tests 109 confirmed that the sand itself had no reactivity towards NO reduction. NO reduction experiments 110 were conducted at three temperatures $\left(800,850,900^{\circ} \mathrm{C}\right)$ and $\mathrm{NO}$ inlet concentrations $(400,800$, $1111500 \mathrm{ppmv}$ ) using 20-50 $\mathrm{mg}$ char with a size of $125-180 \mu \mathrm{m}$ to diminish mass transport resistances.

112 The influence of external and internal mass transfer limitations during NO reduction over char 113 were assessed based on the Maer and Weisz-Prater criteria, respectively. ${ }^{28}$ The results, summarized 114 in the supplemental information (Table S2) for the most reactive biomass, straw, showed that the 115 influence of mass transfer limitations was negligible at the highest applied temperature. Following 116 a reduction experiment, $10 \% \mathrm{O}_{2}$ was introduced the reactor to burn the NO treated char. In 117 addition, separate combustion experiments using $20 \mathrm{mg}, 125-180 \mu \mathrm{m}$ char were carried out at $118800^{\circ} \mathrm{C}$ in $10 \% \mathrm{O}_{2}$. The temperature in the sample bed was assumed constant during combustion in 119 consequence of the low percentage of char in the bed and the high heat capacity of sand. In all 120 experiments, the total volumetric flow rate was $1 \mathrm{NL} / \mathrm{min}$ with the balance gas being $\mathrm{N}_{2}$. The $\mathrm{CO}$, $121 \mathrm{CO}_{2}, \mathrm{O}_{2}$, and $\mathrm{NO}$ concentrations in the dry flue gas were continuously monitored by a series of 122 on-line gas analyzers (NGA2000, Fischer-Rosemount). Moreover, a Fourier Transform Infrared 123 Spectrometer (FTIR) (Multigas 2030 FTIR, MKS instruments) was employed in selected 124 experiments to determine the distribution of nitrogen products during combustion. 
125

126 Figure 1. Schematic illustration of the fixed bed reactor. Adopted from Ulusoy et al. ${ }^{10}$

127 The reactivities of solid fuel chars towards NO are commonly evaluated from globalized first ${ }^{29-32}$ 128 or fractional $12,33,34$ order rate expressions, where the rate constant is most frequently based on the 129 instantaneous mass of carbon in the char. To compare the reactivities between chars, the first order 130 rate constant of the NO-char reaction was determined under the assumption of plug flow, shown 131 in Eq. 1.

133 Here, $\mathrm{X}_{\mathrm{NO}}(-)$ is the instantaneous conversion of $\mathrm{NO}, \mathrm{W}(\mathrm{kg} \mathrm{C})$ the instantaneous char carbon 134 mass in the bed, $\mathrm{v}_{\mathrm{g}}\left(\mathrm{m}^{3} / \mathrm{s}\right)$ the volumetric gas flowrate, and $\mathrm{k}_{\mathrm{NO}}\left(\mathrm{m}^{3} \mathrm{~s}^{-1} \mathrm{kgC}^{-1}\right)$ the first order carbon 135 mass based rate constant. The instantaneous carbon mass was determined from the $\mathrm{CO}$ and $\mathrm{CO}_{2}$ 136 measurements during the reduction section, while the total C-content from a mass balance of the 137 entire experiment.

$138 \quad$ Characterization of chars

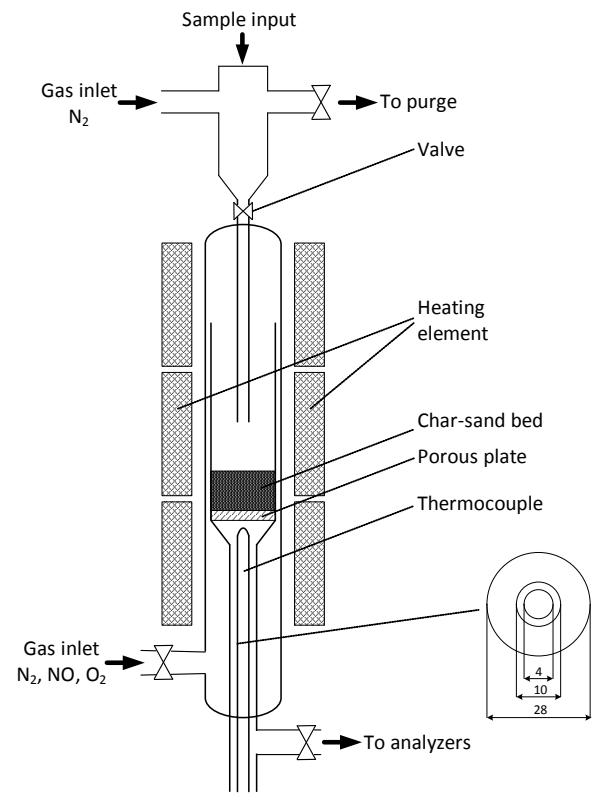


139 The specific Brunauer-Emmett-Teller (BET) surface area and the Barrett-Joyner-Halenda (BJH) 140 mesoporosity of the chars were determined from $\mathrm{N}_{2}$ adsorption at its boiling point $(77 \mathrm{~K})$ in the $141 \mathrm{p} / \mathrm{p}_{0}$ range of 0.01-0.99 using a Quantachrome $\mathrm{iO} 2$ equipment. Prior to measurements, the samples 142 were vacuum degassed at $300^{\circ} \mathrm{C}$ for $5 \mathrm{~h}$. Scanning electron microscopy and energy dispersive $\mathrm{x}-$ 143 ray (SEM-EDX) analysis was performed on a selected number of chars. In the pre-treatment, the 144 chars were coated with platinum, after which they were dried at $105^{\circ} \mathrm{C}$ for one day. X-ray 145 photoelectron spectroscopy (XPS) was conducted on selected chars to analyze the content and 146 functionalities of nitrogen and oxygen on the char surface. The $\mathrm{C} 1 \mathrm{~s}$ and N1s peaks were 147 deconvolved using XPS PEAK 4.1 software by subtracting a Shirley type background and fitting 148 Gaussian-Lorentzian mix functions. The nitrogen functionality was determined from 395-408 eV, 149 in which five distinct nitrogen peaks, pyridinic N-6 (398.7 \pm 0.3$)$, pyrrolic N-5 (400.3 \pm 0.3$)$, 150 quartenary N-Q (401.4 \pm 0.5$)$, oxides N-X1 and N-X2 (402-405), were assigned. ${ }^{35}$ The parameters 151 used for the fitting were the peak width, position, and full-width-half-maximum (FWHM). The 152 Gaussian-Lorentzian (G/L) mix, describing instrumental and metallic effects, was set at 0.7 , i.e. $15370 \%$ Gaussian and 30\% Lorentzian for all nitrogen functionalities.

154 The chemical composition of the chars was analysed with a Thermo Scientific Flash 2000 155 Organic Elemental Analyser (Flash 2000) for the carbon, hydrogen, nitrogen, and sulphur content, 156 while the inorganic contents were determined by inductively coupled plasma emission 157 spectroscopy (ICP-OES).

158 Table 2 summarizes the chemical analyses of the chars, including selected ICP-OES results. The 159 demineralized chars exhibited a lower ash content in comparison with the raw chars. Straw, bran, 160 sunflower seed, and DDGS chars contained large amounts of potassium, which is presumably the 161 most active catalytic element in the char-NO reaction. In comparison, the demineralized chars 
162 were largely depleted of elements presumed to have a catalytic effect on the NO reduction, i.e. 163 potassium, iron, calcium, sodium, and magnesium.

164 Table 2. Char elemental and proximate analyses of six raw and demineralized biomass.

\begin{tabular}{|c|c|c|c|c|c|c|c|c|c|c|c|c|c|}
\hline \multirow[b]{2}{*}{ Char } & \multicolumn{7}{|c|}{ [wt \% d.b.] } & \multicolumn{6}{|c|}{ [mg/kg d.b.] } \\
\hline & $\bar{C}$ & $\mathbf{H}$ & $\mathbf{N}$ & $\mathbf{O}$ & $\mathbf{S}$ & Ash & Char yield & $\bar{K}$ & $\mathbf{P}$ & Mg & $\mathrm{Ca}$ & $\mathbf{F e}$ & $\mathbf{N a}$ \\
\hline Pine wood & 85.7 & 1.48 & 0.11 & 9.12 & 0.0 & 3.59 & 20.5 & 1,083 & 210 & 515 & 4,008 & 223 & 373 \\
\hline Straw & 71.2 & 1.18 & 0.50 & 8.42 & 0.0 & 18.7 & 25.8 & 43,642 & 2,789 & 2,329 & 4,459 & $<3$ & 740 \\
\hline Waste wood & 70.0 & 1.17 & 1.06 & 18.4 & 0.0 & 9.36 & 20.8 & 1,977 & 355 & 3,505 & 32,002 & 4,426 & 1,152 \\
\hline Bran & 59.9 & 1.30 & 2.90 & 9.90 & 0.0 & 26.0 & 26.5 & 69,610 & 49,429 & 18,304 & 3,629 & 676 & $<120$ \\
\hline Sunfl. seed & 57.0 & 1.10 & 3.59 & 11.2 & 0.0 & 27.1 & 29.4 & 55,749 & 29,190 & 17,100 & 18,101 & 2,446 & 550 \\
\hline DDGS & 59.0 & 1.30 & 5.36 & 13.2 & 0.0 & 21.1 & 26.9 & 31,430 & 31,355 & 11,779 & 3,758 & 443 & 11,697 \\
\hline $\begin{array}{l}\text { DM pine } \\
\text { wood }\end{array}$ & 87.5 & 1.56 & 0.11 & 10.7 & 0.0 & 0.11 & 15.8 & $<20$ & $<60$ & $<0.2$ & 90 & 442 & $<120$ \\
\hline DM straw & 82.2 & 1.53 & 0.83 & 7.04 & 0.0 & 8.40 & 16.9 & 76 & 450 & $<0.2$ & 212 & 77 & $<120$ \\
\hline $\begin{array}{l}\text { DM waste } \\
\text { wood }\end{array}$ & 74.8 & 1.23 & 0.84 & 16.5 & 0.0 & 6.59 & 17.4 & 245 & 194 & 1,606 & 8,845 & 1,483 & $<120$ \\
\hline DM bran & 76.9 & 1.49 & 3.52 & 7.69 & 0.0 & 10.4 & 25.7 & 129 & 13,702 & 32 & 96 & 1,047 & $<120$ \\
\hline $\begin{array}{l}\text { DM sunfl. } \\
\text { seed }\end{array}$ & 71.7 & 1.24 & 4.50 & 8.26 & 0.0 & 14.3 & 25.0 & 874 & 14,327 & 485 & 1,400 & 2,275 & $<120$ \\
\hline DM DDGS & 73.3 & 1.35 & 6.92 & 9.58 & 0.0 & 8.85 & 23.8 & $<20$ & 8,402 & $<0.2$ & 87 & 540 & $<120$ \\
\hline
\end{tabular}

Table 3 shows the physical properties of the chars. In general, the surface area and pore volume

167 were noted to increase due to demineralization. The only exception to this was in the case of pine

168 wood, where demineralized pine wood char showed a significantly lower surface area and pore

169 volume, the reasoning of which is unknown. The large pore volume in some chars was primarily

170 due to the formation of micropores in addition to mesopores during charring. A wide range of

171 surface areas and pore volumes are covered by the investigated chars.

172 Table 3: BET surface area (SA), pore volume $\left(\mathrm{V}_{\mathrm{p}}\right)$, and mean pore diameter $\left(\mathrm{d}_{\mathrm{p}, \text { mean }}\right)$ of the chars. 
1

2

3

4

5

6

7

8

9

10

11

12

13

14

15

16

17

18

19

20

21

22

23

24

25

26

27

28

29

30

31

32

33

34

35

36

37

38

39

40

41

42

43

44

45

46

47

48

49

50

51

52

53

54

55

56

57

58

59

60

\begin{tabular}{lccc} 
Char & $\mathbf{S A}\left[\mathbf{m}^{\mathbf{2}} / \mathbf{g}\right]$ & $\mathbf{V}_{\mathbf{P}}\left[\mathbf{c m}^{\mathbf{3}} / \mathbf{g}\right]$ & $\mathbf{d}_{\mathbf{p}, \text { mean }}[\mathbf{n m}]$ \\
\hline Pine wood & 405 & 0.18 & $1.076 / 3.377$ \\
Straw & 25 & $2.4 \cdot 10^{-2}$ & 3.404 \\
Waste wood & 91 & $5.8 \cdot 10^{-2}$ & 4.275 \\
Bran & 4.5 & $6.1 \cdot 10^{-3}$ & 3.054 \\
Sunfl. seed & 1.2 & $2.7 \cdot 10^{-3}$ & 3.855 \\
DDGS & 1.0 & $1.2 \cdot 10^{-3}$ & 3.087 \\
DM pine wood & 4.5 & $6.5 \cdot 10^{-3}$ & 3.059 \\
DM straw & 430 & 0.18 & $1.932 / 3.382$ \\
DM waste wood & 415 & 0.18 & $1.178 / 3.383$ \\
DM bran & 3.0 & $3.1 \cdot 10^{-3}$ & 3.379 \\
DM sunfl. seed & 135 & $6.8 \cdot 10^{-2}$ & 3.374 \\
DM DDGS & 4.6 & $4.7 \cdot 10^{-3}$ & 3.440
\end{tabular}

173

ACS Paragon Pl2 2 Es Environment 


\section{$174 \quad$ Results}

\section{Conversion of char-N to NO}

176 Figure 2 illustrates the conversion of char-N to NO during combustion of raw (a) and 177 demineralized (b) chars in $10 \% \mathrm{O}_{2}$, along with error bars depicting the deviations in the elemental 178 analyses. The results indicate that the conversion of char-N to NO decreased with an increase in 179 char-N content, in accordance with previous single particle combustion studies. ${ }^{8,21}$ This trend was 180 also observed for the demineralized chars at both investigated temperatures. At higher temperature, 181 a slight increase in the conversion of char-N to NO was observed. Previous studies on coal chars 182 showed that the effect of temperature was negligible when increased from 800 to $900^{\circ} \mathrm{C},{ }^{36}$ while 183 it could be more pronounced when changing from 850 to $1150^{\circ} \mathrm{C} .{ }^{5}$ According to the mechanism 184 shown in R1-R9, the observed trends are conceivably related to the NO formation and/or reduction 185 reactions. In the demineralized chars, i.e., with a diminished impact of inorganic elements, it could 186 be expected that R4 and R5 occur more rapidly when high local concentrations (-CN) and NO are 187 prominent. Alternatively, nitrogen-rich compounds could form a higher concentration of 188 alternative combustion products such as $\mathrm{N}_{2} \mathrm{O}, \mathrm{N}_{2}$, and $\mathrm{NO}_{2}$. Lastly, the lower conversion to $\mathrm{NO}$ 189 could be caused by the combustion atmosphere, e.g. simultaneous presence of high $\mathrm{O}_{2}$ and $\mathrm{CO}$ 190 concentrations, thereby increasing the importance of R6 and R9, respectively. In the following 191 sections, the combustion product distribution and NO reduction reactivity of the chars were 192 examined to provide insight into the decreasing conversion of char-N to NO. 
(a) Raw char

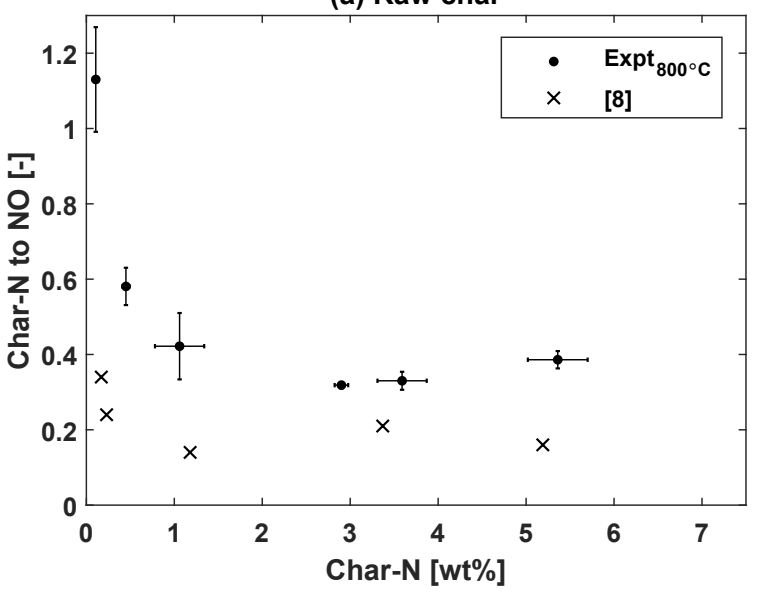

(b) DM char

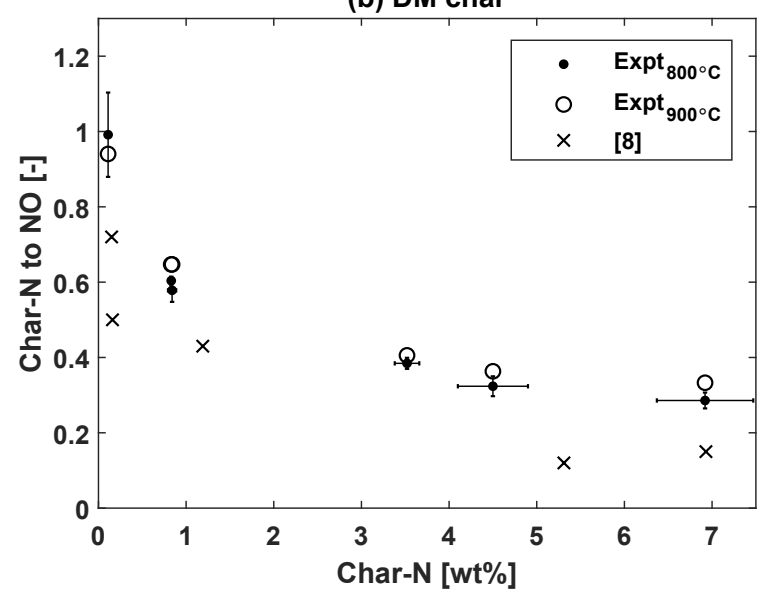

193

207 is consistent with reported coal char combustion studies.,39 In addition, a slightly higher

208 conversion to $\mathrm{N}_{2} \mathrm{O}$ was observed for the demineralized chars, presumably caused by the promoting 209 effect of ash forming elements such as potassium on the $\mathrm{N}_{2} \mathrm{O}$ reduction over char. ${ }^{40}$ 
(a) Raw char

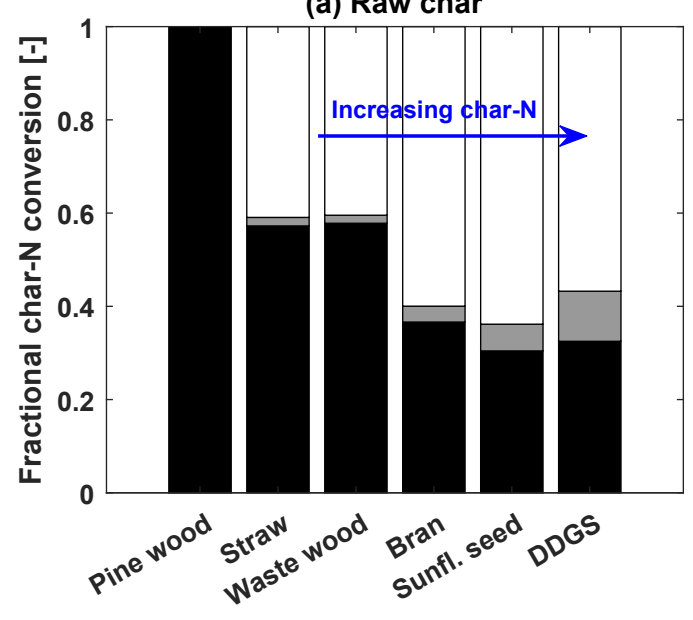

(b) DM char

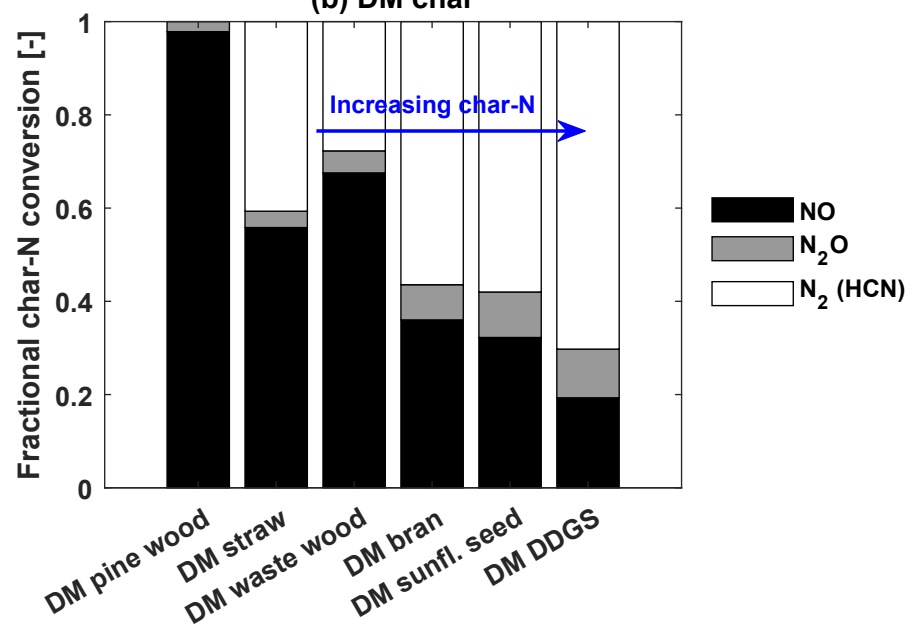

211 Figure 3. Distribution of nitrogen products from $20 \mathrm{mg}$ char combustion at $800^{\circ} \mathrm{C}$ in $10 \mathrm{vol} \% \mathrm{O}_{2}$.

212 Figure 4 illustrates the fractional conversion of char- $\mathrm{N}$ to $\mathrm{NO}$ and $\mathrm{N}_{2} \mathrm{O}$, and the ratio of $\mathrm{N}_{2} \mathrm{O}$ to

213 the total $\mathrm{NO}_{\mathrm{X}}\left(\mathrm{NO}+\mathrm{N}_{2} \mathrm{O}\right)$ during combustion of selected chars at varying char mass. By reducing

214 the char mass, a smaller degree of reduction of the formed nitrogen oxidation products by

215 secondary char particles is expected. The results show that high amounts of $\mathrm{N}_{2} \mathrm{O}$ were formed

216 during char combustion; in one case, as much as $25 \%$ of the char- $\mathrm{N}$ formed $\mathrm{N}_{2} \mathrm{O}$. The conversion

217 of char- $\mathrm{N}$ to $\mathrm{NO}$ and $\mathrm{N}_{2} \mathrm{O}$ generally increased with a decrease in char mass. In addition, the ratio

218 of $\mathrm{N}_{2} \mathrm{O}$ to the total $\mathrm{NO}_{\mathrm{X}}$ was higher for the high-nitrogen DDGS chars and decreased with an

219 increase in char mass, due to the faster decomposition of $\mathrm{N}_{2} \mathrm{O}$ to $\mathrm{N}_{2}$ over char (R10 ${ }^{39}$ and $\left.\mathrm{R} 11^{15}\right)$

220 compared to NO. ${ }^{41}$ As the reduction of reactive nitrogen combustion products by secondary char

221 particles was small at low char mass, the results indicate that the inherent conversion of char-N to

$222 \mathrm{~N}_{2} \mathrm{O}$ increased for a char size range of 125-180 $\mu \mathrm{m}$. For different char sizes, the reduction within

223 the parent char particle could be affected. ${ }^{42}$ Two mechanisms have been proposed for the formation

224 of $\mathrm{N}_{2} \mathrm{O}$ during char combustion. ${ }^{4}$ In the homogeneous mechanism, HCN or $\mathrm{HNCO}$ is released

225 during char combustion, followed by reaction of the NCO radical with NO to form $\mathrm{N}_{2} \mathrm{O}$ ( $\mathrm{R} 12$ -

226 R13). ${ }^{43}$ The heterogeneous mechanism involves the dissociative adsorption of $\mathrm{O}_{2}$, followed by 
227 reaction of the surface complex (-CNO) with a (-CN) site (R14) or NO molecule (R15). Negligible 228 amounts of $\mathrm{N}_{2} \mathrm{O}$ was detected by the reaction between $\mathrm{NO}$ and $(-\mathrm{CN})$ without the presence of $229 \mathrm{O}_{2 ;}^{12,44,45}$ this finding was verified by selected reduction experiments in this study. The relative 230 importance R12-R13 and R14-R15 is yet unknown. ${ }^{15}$ The larger amount of $\mathrm{N}_{2} \mathrm{O}$ formed from 231 combustion of high-nitrogen chars could possibly be explained by the high local concentrations of $232 \mathrm{HCN}$ and $\mathrm{NO}$, or $\mathrm{NO},(-\mathrm{CN})$, and (-CNO). Consequently, with an increase in char- $\mathrm{N}$ a higher 233 fraction of char- $\mathrm{N}$ is inherently converted to $\mathrm{N}_{2} \mathrm{O}$, which is more readily reduced over char, thereby 234 partly explaining the decrease in char-N to NO conversion with increasing char-N content. Besides 235 affecting NO formation, a higher char-N content could conceivably enhance the NO reduction 236 reactivity of the chars, which was further examined.

$$
\begin{array}{rll}
\mathrm{N}_{2} \mathrm{O}+(-\mathrm{C}) & \rightarrow \mathrm{N}_{2}+(-\mathrm{CO}) & \mathrm{R} 10 \\
\mathrm{~N}_{2} \mathrm{O}+\mathrm{CO} & \rightarrow \quad \mathrm{N}_{2}+\mathrm{CO}_{2} \quad \text { (over char) } & \mathrm{R} 11 \\
\mathrm{HCN}+\mathrm{O}, \mathrm{OH} & \rightarrow \mathrm{NCO}+\mathrm{H}, \mathrm{H}_{2} \mathrm{O} & \mathrm{R} 12 \\
\mathrm{NCO}+\mathrm{NO} & \rightarrow \quad \mathrm{N}_{2} \mathrm{O}+\mathrm{CO} & \mathrm{R} 13 \\
(-\mathrm{CN})+(-\mathrm{CNO}) & \rightarrow \mathrm{N}_{2} \mathrm{O}+2(-\mathrm{C}) & \mathrm{R} 14 \\
\mathrm{NO}+(-\mathrm{CNO}) & \rightarrow \mathrm{N}_{2} \mathrm{O}+(-\mathrm{CO}) & \mathrm{R} 15
\end{array}
$$


(a) DDGS char

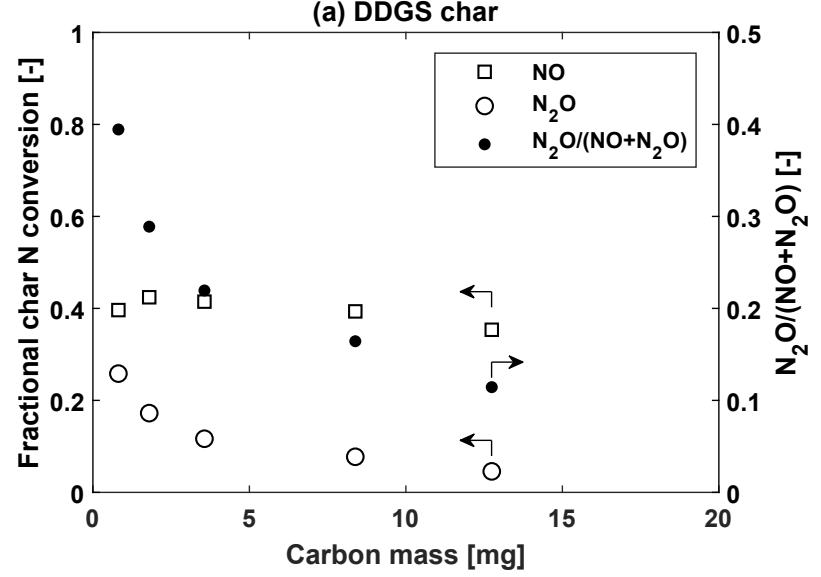

(c) Straw char

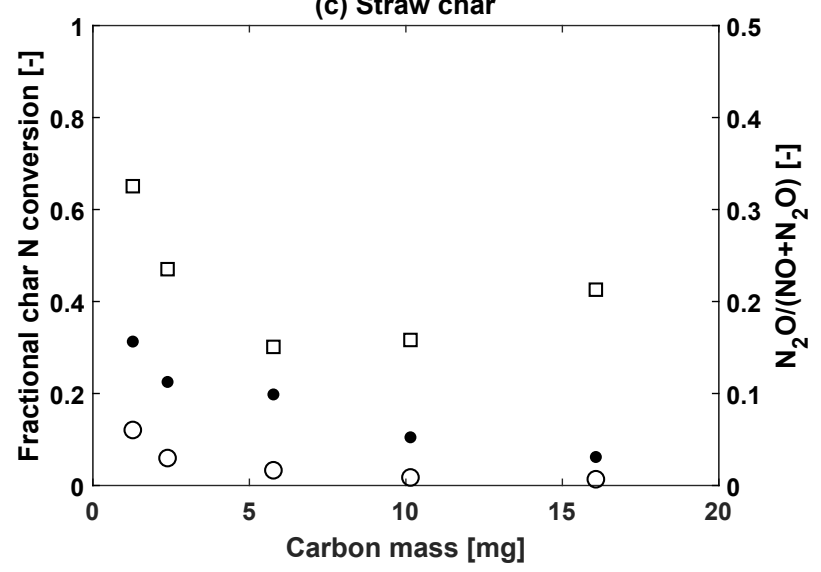

(b) DM DDGS char

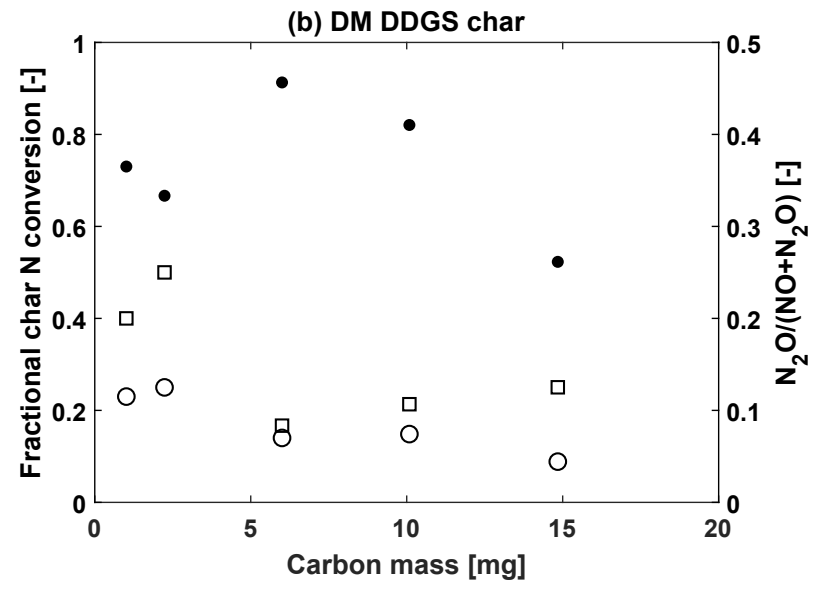

(d) DM straw char

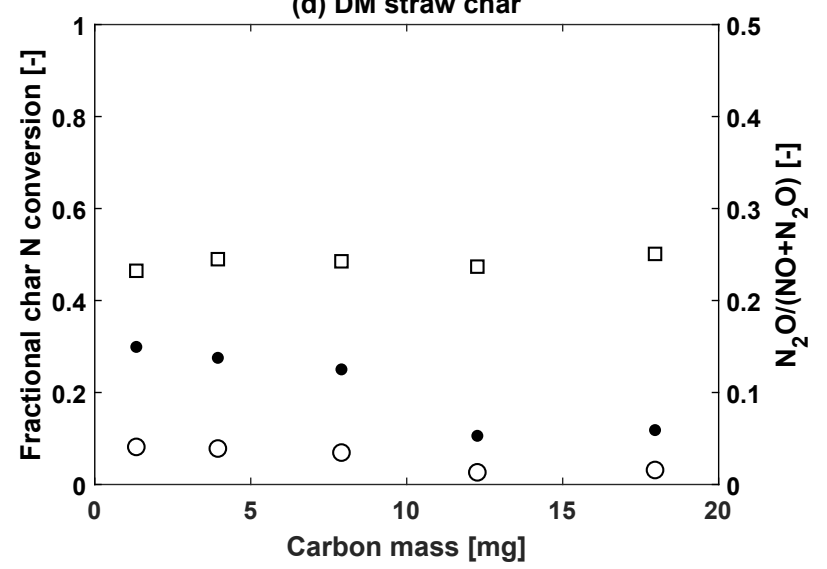

238 Figure 4. Conversion of char- $\mathrm{N}$ to $\mathrm{NO}$ and $\mathrm{N}_{2} \mathrm{O}$ during combustion of DDGS (a), DM DDGS (b),

239 straw (c), and DM straw (d) chars at varying mass at $800^{\circ} \mathrm{C}$ using $10 \mathrm{vol} \% \mathrm{O}_{2}$.

$240 \quad$ Reduction of NO over raw and DM biomass chars

241 Figure 5 illustrates the conversion of 400 ppmv NO over the raw (a) and demineralized (b)

242 biomass chars at $800^{\circ} \mathrm{C}$. Of the raw biomass chars, the conversion of $\mathrm{NO}$ is high for straw, waste

243 wood, and sunflower seed, while lower for bran, pine wood, and DDGS. The demineralized chars

244 exhibited lower reduction in comparison to the raw chars and less discrepancy between different

245 fuel chars. The maximum relative standard error between repetitions was determined to be $4 \%$,

246 demonstrated in the supplemental material (Figure S1). Based on the inherent nitrogen content of

247 the chars in Table 2 and the conversion of char-N to NO in Figure 2, it was suspected that the 
248 reduction reactivity of the demineralized chars in decreasing order would be DM DDGS, DM 249 sunflower seed, DM bran, DM waste wood, DM straw, DM pine wood.

250 Figure $5 \mathrm{c}$ and $\mathrm{d}$ present the reactivity on a carbon mass basis of the chars at $800^{\circ} \mathrm{C}$ using 400 251 ppmv NO, calculated by Eq. 1. The difference in the raw chars was again more pronounced than 252 that of the demineralized chars. For a majority of the chars, a high transient reactivity followed by 253 a steady state is observed. This has previously been attributed to thermal deactivation, initial 254 accumulation of $\mathrm{NO}$ on the char surface, or formation of thermally stable surface oxides. ${ }^{4,33}$ In 255 addition, mixing and delay of the gas stream downstream of the reactor contribute to the duration 256 of this phase. The straw displayed the highest reactivity towards NO, presumably due to the large 257 potassium content. Although the potassium in bran exceeded that of the straw, their reactivities 258 differed significantly; this is further examined in the following sections. In addition, different 259 transient behaviors of the chars was observed. In some cases, a distinct steady state was observed, 260 e.g. bran and pine wood, while for other chars, e.g., from straw and waste wood, the reactivity 261 significantly decreased with time. This in turn suggests that some chars are more prone to 262 deactivation, possibly related to the transformation of catalytic inorganic species, which needs to 263 be further studied. To correlate the observed trends in reactivity with the physiochemical properties 264 of the chars, the transient reactivity was defined as the maximum rate constant. This reactivity was 265 preferred over the steady state reactivity to minimize effects from long term, high temperature 266 exposure. However, the conclusions for the transient reactivity also apply to the steady state 267 reactivity. In addition, the influence of temperature and inlet NO concentration on the NO 268 reduction reactivity of the chars was investigated. The results are generally in consensus with 269 previous studies ${ }^{4,12}$ and can be seen in the supplemental material (Figure S2 and S3). Although the 270 reactivities were dependent on the NO inlet concentrations, the first order rate constant can be used 
271 as a qualitative comparison of the char reactivity under similar NO concentration. For modelling 272 purposes, other rate expressions such as fractional order, concentration averaged, or mechanistic 273 models may be used to capture the effect of NO inlet concentration.

(a) Raw char

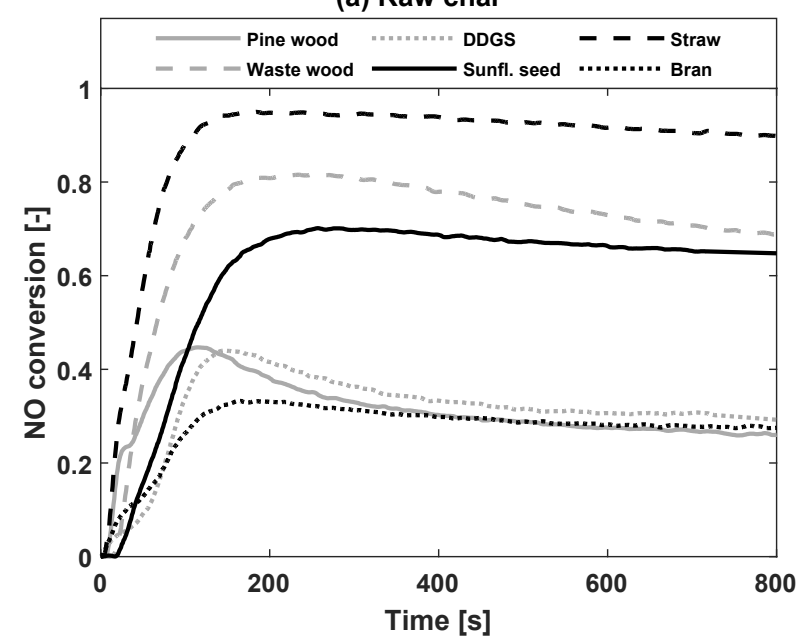

(c) Raw char

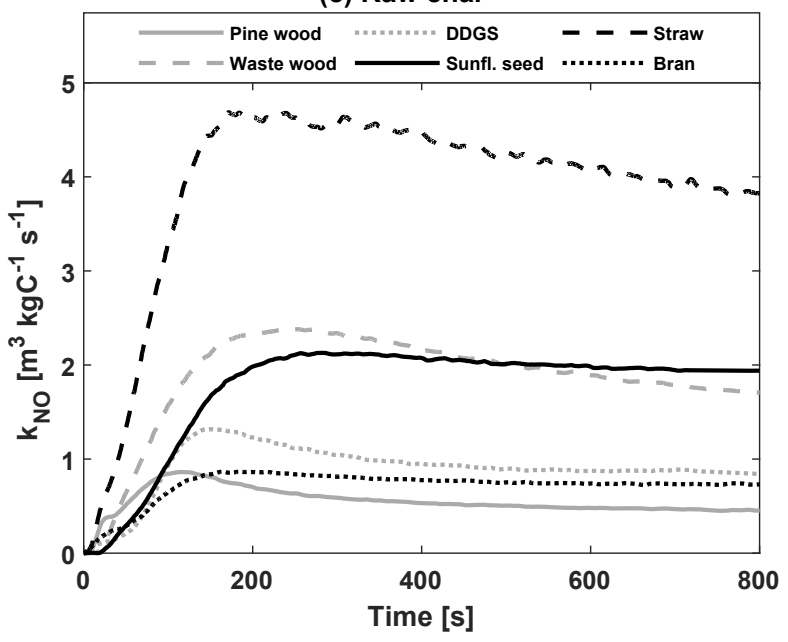

(b) DM char

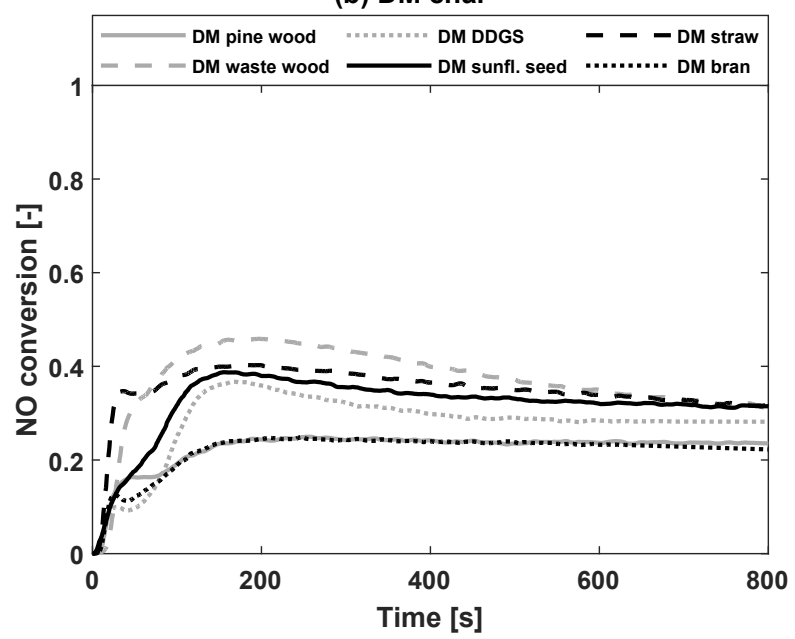

(d) DM char

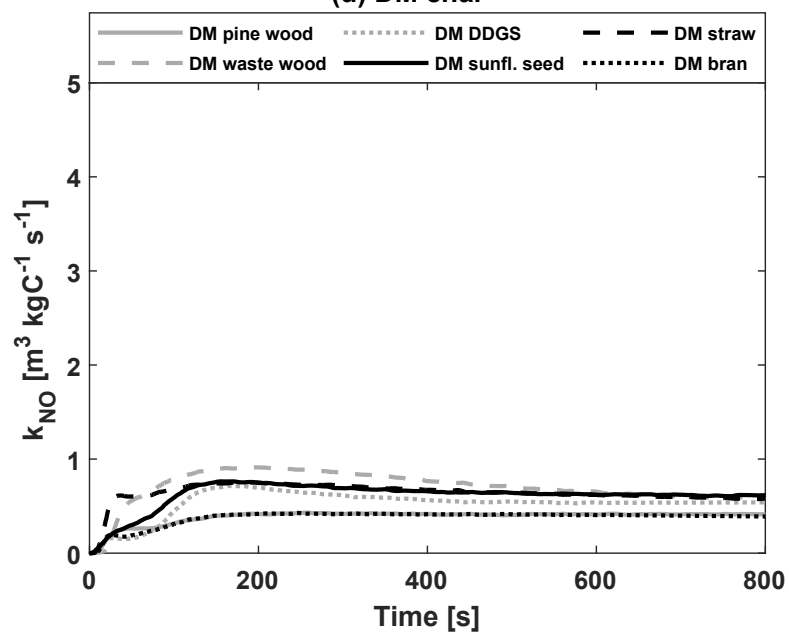

275 Figure 5. Conversion of NO over $50 \mathrm{mg}$ raw (a) and DM (b) chars at $800^{\circ} \mathrm{C}$ using an NO inlet 276 concentration of $400 \mathrm{ppmv}$ NO. First order carbon mass based NO reduction rate constant $\left(\mathrm{k}_{\mathrm{NO}}\right)$

277 against time for raw (c) and DM (d) chars at $800^{\circ} \mathrm{C}$ and 400 ppmv NO.

278 Influence of initial surface area and char-N content on NO reduction 
279 Figure 6 demonstrates the reactivity as a function of BET surface area. A direct correlation 280 between the reactivity and the initial BET surface area was not observed for any of the chars. As 281 the surface areas of the chars were prone to change during reaction either by thermal annealing or 282 pore opening, it may not be possible to rule out the effect of surface area on the NO reduction. 283 Therefore, the relevant or active instantaneous surface area could provide a better basis for 284 reactivity especially for the non-catalytic, demineralized chars. ${ }^{46}$ A previous study suggested that 285 the reactivity of chars towards NO correlated better with the specific surface area of the meso and 286 macropores (>50 nm) determined by mercury intrusion..$^{20}$

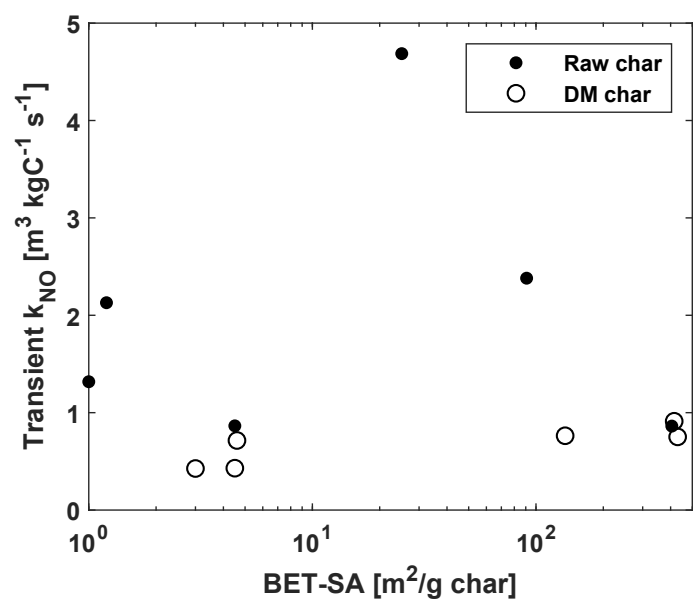

288 Figure 6. First order, transient NO reduction reactivity of DM and raw biomass chars against the 289 BET surface area expressed in $\mathrm{m}^{2} / \mathrm{g}$. The rate constants were determined at $800^{\circ} \mathrm{C}$ using an $\mathrm{NO}$ 290 inlet concentration of 400 ppmv.

291 Figure 7 demonstrates the reactivity of the demineralized and raw chars against the initial char292 N content. No correlation was observed between the reactivity and the initial char-N content. In 293 addition, no correlation was observed between the reactivity, and the product and ratio of char-N 294 content and surface area, seen in the supplemental material (Figure S4). For the raw chars, the 295 reasoning for this is most likely due to the stronger impact of catalytic elements. In comparison, 
296 the demineralized chars showed a smaller discrepancy. The small differences in reactivity are 297 presumably caused by distinct physical or chemical properties, all of which are prone to change 298 during experimentation. Possible influential factors are the surface area, pore size distribution, and 299 surface chemistry, the latter of which includes elemental population and functionality. Based on 300 the results on the conversion of char-N to NO and the proposed reduction mechanism (R3-R9), it 301 was hypothesized that a higher nitrogen content (-CN) would lead to a higher reduction reactivity 302 of the demineralized chars through R4 and R5. The results here show no direct correlation between 303 reactivity and initial char-N content. Although, the reactivities at $800^{\circ} \mathrm{C}$ are shown in Figures 6 304 and 7 , the conclusions drawn here also apply at $900^{\circ} \mathrm{C}$. Pevida et al. ${ }^{47}$ reported a similar 305 observation in their study, noting that the reactivities of model chars with and without (-CN) were 306 quite similar. Hence, they concluded that the inherent nitrogen content had a small effect on the 307 reduction reaction. The reduction reactivity of the accumulated $(-\mathrm{CN})$ sites could be different 308 relative to the inherent $(-\mathrm{CN})$ sites, thereby explaining why no correlation to the inherent char-N 309 content was observed. The buildup of (-CN) sites during NO reduction was demonstrated in this 310 study by the combustion of NO treated and untreated chars at $900^{\circ} \mathrm{C}$. From these experiments, it 311 was noted that the conversion of char-N to NO systematically increased with the concentration of 312 NO during reduction experimentation, seen in Figure 8. The systematic increase in conversion was 313 most likely caused by surface enrichment of $(-\mathrm{CN})$ and $(-\mathrm{CO})$ species during the NO reduction. 314 Previous studies indicated a temperature dependent buildup of both (-CN) and (-CO) species 315 during the NO-char reaction, during which the accumulation of $(-\mathrm{CN})$ was greater than $(-\mathrm{CO})$ at 316 temperatures above $750^{\circ} \mathrm{C},{ }^{7,48} \mathrm{An}$ increase in $(-\mathrm{CN})$ would increase the amount of NO formed 317 from combustion, while (-CO) could have a promoting or inhibiting effect on the NO reduction, 
318 depending on the bond strength. In the following section, the type and importance of the inherent 319 surface nitrogen functionality is discussed.

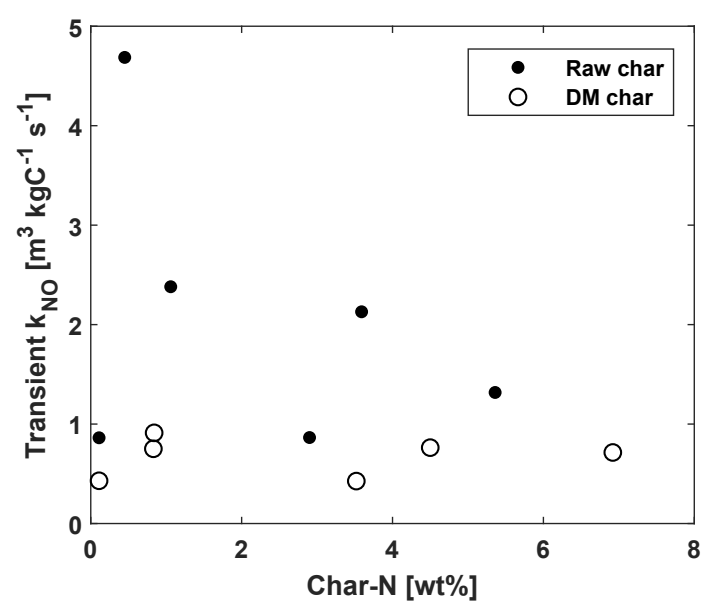

321 Figure 7. First order, transient NO reduction reactivity of DM and raw biomass chars against the 322 initial nitrogen content. The rate constants were determined at $800^{\circ} \mathrm{C}$ using an NO inlet 323 concentration of 400 ppmv.

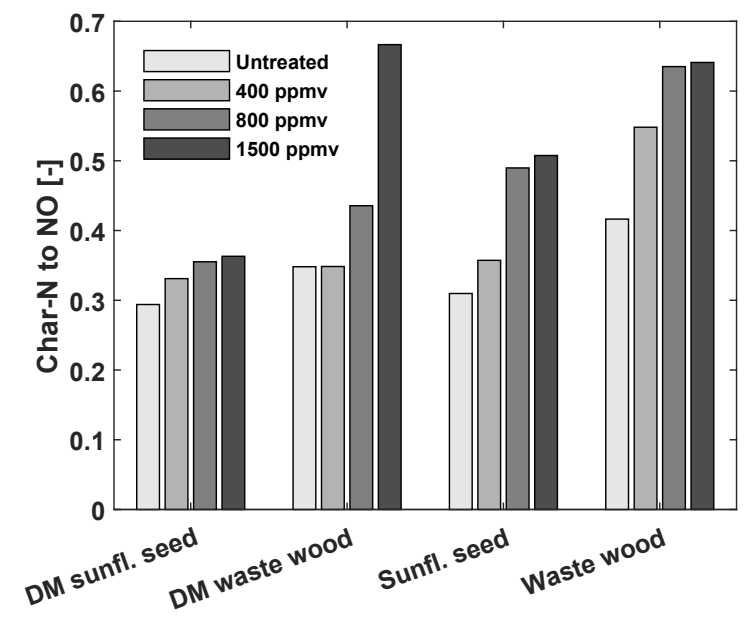

325 Figure 8. The conversion of char-N to $\mathrm{NO}\left(\mathrm{F}_{\mathrm{NO}}\right)$ from combustion of NO treated and untreated 326 chars. $F_{N O}=\int_{0}^{t_{\text {final }}} \mathrm{NOdt} /\left[\int_{0}^{t_{\text {final }}} \mathrm{CO}+\mathrm{CO}_{2} d t \cdot\left(\frac{N}{C}\right)_{\text {char }}\right]$. Conditions of combustion: $900^{\circ} \mathrm{C}, 10 \mathrm{vol} \%$ $327 \mathrm{O}_{2}$. Conditions of NO treatment: $900^{\circ} \mathrm{C},[400 ; 1500] \mathrm{ppmv}$ NO. 


\section{Influence of char nitrogen and oxygen functionality on NO reduction}

329 Figure 9 displays the nitrogen functionality as determined by XPS. All chars contained large 330 amounts of pyridinic (N6), pyrrolic (N5), and quartenary (NQ) nitrogen with differences in the 331 relative distributions of these. In general, the relative abundance of N6 and NQ in chars increases

332 with the severity of heat treatment, i.e., temperature and holding time, due to the thermal stabilities 333 of these compounds. ${ }^{35,49,50}$ The results here show a small discrepancy between the demineralized 334 samples with the only exception being DM pine wood. Notably, the nitrogen content in this char 335 was low, thereby raising question as to the usability of a deconvolution method for extracting 336 functionality data, seen in supplemental material (Figure S5). Nonetheless, the results are shown 337 here and treated critically in the correlation studies described below. In addition, the 338 demineralization changed the nitrogen functionalities in the resulting char in the case of straw, 339 while a lesser impact was observed for bran and sunflower seed. Previously, deashing of coals and 340 their respective chars using stronger acids such as $\mathrm{HCl}$ and $\mathrm{HF}$ showed little or no change in the 341 nitrogen functionality. ${ }^{51}$ Thus, the change in nitrogen functionality for straw could therefore be 342 due to the influence of ash forming elements on the pyrolysis, rather than the demineralization 343 process itself.

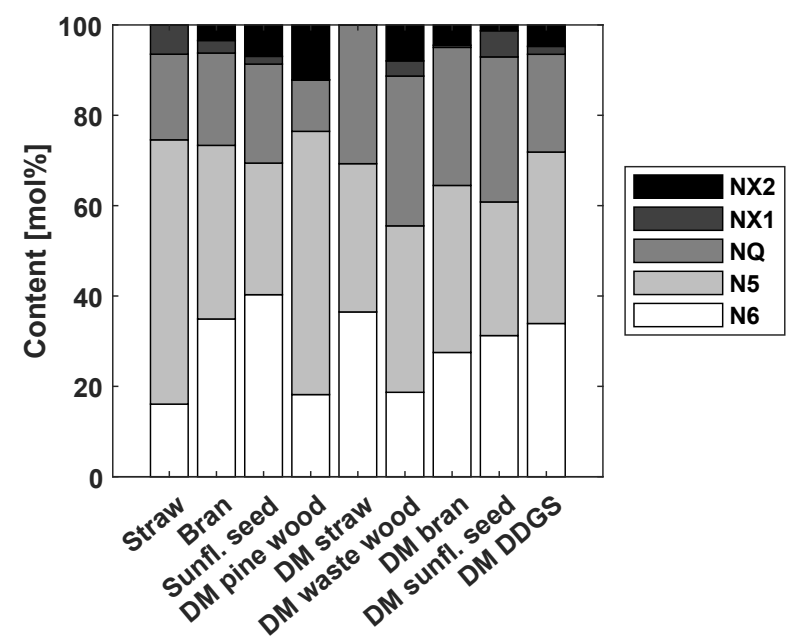


345 Figure 9. Surface nitrogen distribution as measured by XPS for selected raw and all demineralized 346 chars.

347 Several studies have concluded that no correlation exists between the char-N functionality and 348 NO emission in an oxidizing atmosphere. ${ }^{15,52-55}$ This has primarily been attributed to the larger 349 influence of other factors such as physical properties, catalytic effects, and NO reduction over 350 char. ${ }^{15}$ This study also implies a lack of correlations between the surface nitrogen/oxygen 351 functionality and the measured NO formation and reduction, as shown in the supplemental material 352 (Table S3-S4 and Figure S6-S7). Instead the char-N content was again determining for the 353 fractional conversion to $\mathrm{NO}$ and $\mathrm{N}_{2} \mathrm{O}$ during char combustion (Figure S8), further explained in the 354 discussion section. 
355 Influence of ash forming element content and association on NO reduction

356 It was previously stated that potassium, calcium, iron, magnesium, and sodium can catalyze the 357 reduction of NO over char, most likely through reactions R7 and R8. Although, bran char contained 358 considerably higher amounts of potassium and magnesium, and comparable amounts of calcium, 359 iron, and sodium as straw char, the reactivity was significantly lower. A contributing factor to this 360 could be the much larger phosphorous content in bran, which could capture the potassium and 361 form presumably catalytically less active compounds, e.g., $\mathrm{KPO}_{3} .{ }^{56} \mathrm{~A}$ similar reasoning would 362 describe the observed differences between the high-phosphorous sunflower seed and DDGS chars, 363 and low-phosphorous straw char. To investigate this hypothesis, the surface composition of 364 catalytic elements were examined using SEM-EDX measurements, illustrated in Figure 10 and 365 Table 4. The straw char contained a rougher surface structure compared to the smoother bran char, 366 thus explaining the smaller surface area of the latter. Both bran and straw char contained a large 367 quantity of potassium on the surface, while bran char additionally showed a large phosphorous 368 content. The ratio between these elements was approximately $1: 1$, thereby possibly indicating the 369 presence of $\mathrm{KPO}_{3}$ on the bran char surface, while the potassium in straw char was primarily present 370 as organic- $\mathrm{K}, \mathrm{KCl}$, and to lesser extent $\mathrm{K}_{2} \mathrm{SO}_{4}$ and higher order minerals. As the magnitude of the 371 surface areas of straw and bran char was comparable, the results here suggest that $\mathrm{KPO}_{3}$ in bran 372 char caused the lower NO reduction reactivity compared to straw char. However, further studies 373 are necessary to clarify the influence of phosphorous on the NO reduction reactivity of chars. 
376 Table 4. EDX results in connection to Figure 10.

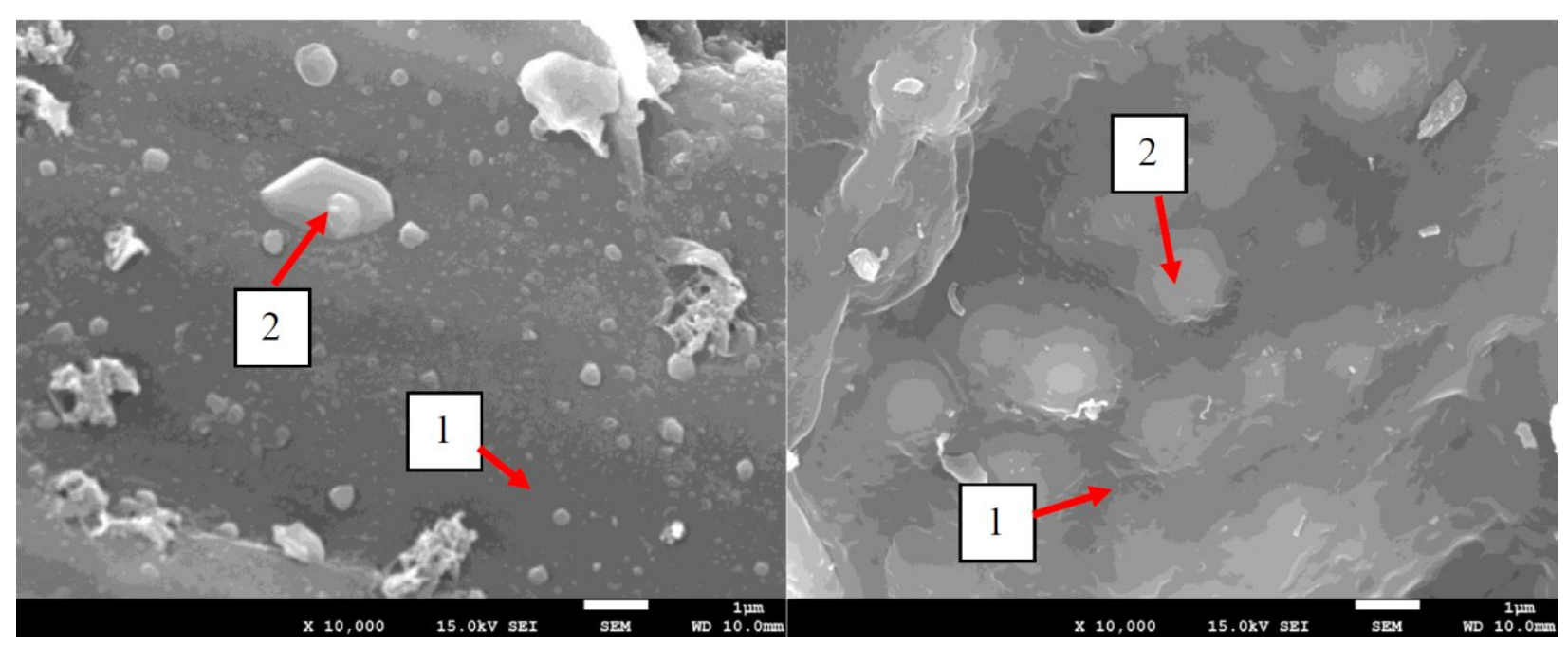

Figure 10. SEM-EDX measurements of straw (left) and bran (right)

\begin{tabular}{lllllllll} 
& \multicolumn{8}{c}{$[\mathrm{at} \%]$} \\
\cline { 2 - 9 } Char & $\mathbf{K}$ & $\mathbf{P}$ & $\mathbf{M g}$ & $\mathbf{C a}$ & $\mathbf{F e}$ & $\mathbf{N a}$ & $\mathbf{C l}$ & $\mathbf{S}$ \\
\hline Straw 1 & $\mathbf{6 . 7}$ & $\mathbf{1 . 7}$ & 0.90 & 0.87 & 0.00 & 0.15 & 4.9 & 0.2 \\
Straw 2 & $\mathbf{3 . 5}$ & $\mathbf{0 . 1}$ & 0.04 & 0.01 & 0.00 & 0.01 & 1.1 & 0.1 \\
Bran 1 & $\mathbf{7 . 0}$ & $\mathbf{7 . 1}$ & 1.10 & 0.51 & 0.07 & 0.01 & 0.03 & 0.1 \\
Bran 2 & $\mathbf{4 . 6}$ & $\mathbf{5 . 8}$ & 2.49 & 0.28 & 0.05 & 0.01 & 0.02 & 0.1
\end{tabular}

378 To determine the influence of ash forming element association in the raw straw, a sequential 379 leaching method was employed. Table 5 summarizes selected chemical and physical properties of 380 the raw and washed straw chars, along with the NO reduction reactivities. The results show that 381 the ash content decreased with the severity of pre-treatment. Potassium, phosphorous, and sodium 382 in the straw were predominately water soluble, while magnesium and to some extent calcium was 383 organically bound. In addition, the surface area increased from raw to demineralized straw char, 384 most likely due to the formation of micropores as a consequence of pre-treatment. The contribution 
385 of water soluble, organically soluble, acid soluble, and insoluble ash forming elements to the total 386 ash was $44.6 \%, 4.3 \%, 5.9 \%$, and $45.2 \%$, respectively. The presence of the ash forming elements 387 on the surface was verified using SEM-EDX, which additionally showed little change in the 388 morphology of the chars, seen in supplemental material (Figure S9 and S10). All char samples 389 exhibited a rod shaped particle with a porous, tunnel-like structure. In addition, the reactivity 390 decreased with the severity of pre-treatment. As the water soluble elements (secluded alkali or 391 alkaline carbonates, chlorides, sulfates, and hydroxides) in straw had a large contribution to the 392 total ash content, the influence of these on the reduction reactivity were higher. Moreover, the 393 results show that the influence of ash forming elements dominates the reduction reactivity of the 394 chars in comparison to other factors such as surface area and porosity.

395 Table 5. Chemical and physical properties of the sequentially leached chars. The reduction rate 396 constant is the transient values from reduction experiments at $800^{\circ} \mathrm{C}$ using 400 ppmv NO.

\begin{tabular}{|c|c|c|c|c|c|c|c|c|c|c|c|c|c|c|c|c|}
\hline \multirow[b]{2}{*}{ Char } & \multicolumn{6}{|c|}{ [wt\% d.b.] } & \multicolumn{6}{|c|}{ [mg/kg d.b.] } & \multicolumn{3}{|c|}{ Physical properties } & \multirow{2}{*}{$\begin{array}{c}\mathbf{k}_{\mathrm{NO}} \\
{\left[\mathbf{m}^{3}\right.} \\
\left.\mathbf{k g C}^{-1} \mathbf{s}^{-1}\right]\end{array}$} \\
\hline & $\mathbf{C}$ & $\mathbf{H}$ & $\mathbf{N}$ & $\mathbf{O}$ & $\mathbf{S}$ & Ash & $\mathbf{K}$ & $\mathbf{P}$ & $\mathbf{M g}$ & $\mathbf{C a}$ & $\mathrm{Fe}$ & $\mathrm{Na}$ & $\begin{array}{c}\text { BET } \\
{\left[\mathrm{m}^{2} / \mathrm{g}\right]}\end{array}$ & $\begin{array}{c}\mathbf{V}_{\mathbf{P}} \\
{\left[\mathrm{cm}^{3} / \mathrm{g}\right]}\end{array}$ & $\begin{array}{c}\mathbf{d}_{\mathbf{P}, \text { mean }} \\
{[\mathbf{n m}]}\end{array}$ & \\
\hline Straw & 71.2 & 1.18 & 0.50 & 8.42 & 0.0 & 18.7 & 43,642 & 2,789 & 2,329 & 4,459 & $<3$ & 740 & 25 & $2.4 \cdot 10^{-2}$ & 3.404 & 4.7 \\
\hline $\begin{array}{l}\text { WW } \\
\text { straw }\end{array}$ & 78.9 & 1.36 & 0.41 & 8.93 & 0.0 & 10.4 & 3,047 & 235 & 2,175 & 5,714 & 92 & $<120$ & 296 & 0.14 & $\begin{array}{l}1.932 / \\
3.380\end{array}$ & 2.1 \\
\hline $\begin{array}{l}\text { OW } \\
\text { straw }\end{array}$ & 71.7 & 1.29 & 0.50 & 16.9 & 0.0 & 9.60 & $<20$ & 228 & 104 & 1,630 & 154 & $<120$ & 421 & 0.18 & $\begin{array}{l}1.932 / \\
3.389\end{array}$ & 0.97 \\
\hline $\begin{array}{l}\text { DM } \\
\text { straw }\end{array}$ & 82.2 & 1.53 & 0.83 & 7.04 & 0.0 & 8.40 & 76 & 450 & $<0.2$ & 212 & 77 & $<120$ & 430 & 0.18 & $\begin{array}{l}1.932 / \\
3.382\end{array}$ & 0.75 \\
\hline
\end{tabular}

398 The NO reduction reactivity of all chars studied as a function of the molar $(\mathrm{K}+\mathrm{Ca}) / \mathrm{C}$ ratio is 399 shown in Figure 11. In our previous study, the NO reduction reactivity of sewage sludge, RDF, 400 and straw chars correlated well with the molar ratio $(\mathrm{Fe}+\mathrm{K}+\mathrm{Ca}) / \mathrm{C} .{ }^{10}$ As the iron content in the 
401 biomass chars was very low, $\mathrm{Fe}$ was neglected in this study. The results show that the reactivities

402 of the low-phosphorous (pine wood, waste wood, and straw) chars correlated reasonably well with 403 the $(\mathrm{K}+\mathrm{Ca}) / \mathrm{C}$ molar ratio at two temperatures. The reactivities of the raw high-phosphorous (bran, 404 sunflower seed, and DDGS) chars were lower than the regression line, the reasoning of which has 405 been discussed in previous paragraphs. Demineralized chars exhibited a lower discrepancy, 406 thereby showing a lesser impact of phosphorous.

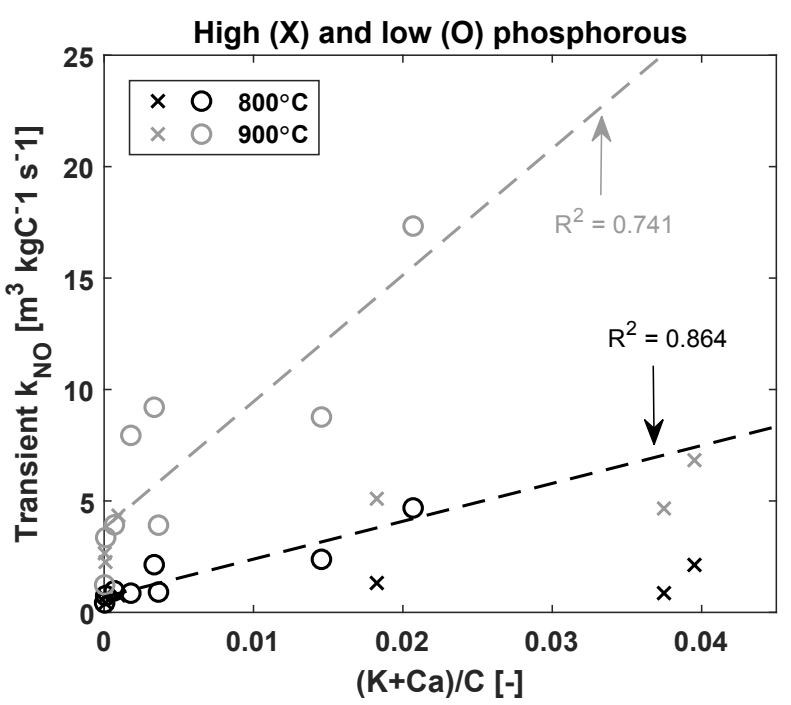

408 Figure 11. First order, transient NO reduction reactivity of all investigated chars at $800^{\circ} \mathrm{C}$ and $409900^{\circ} \mathrm{C}$ using 400 ppmv NO against the molar ratio $(\mathrm{K}+\mathrm{Ca}) / \mathrm{C}$. The regression lines were made 410 solely on the low-phosphorous chars. 


\section{Discussion}

412 Previous studies reported a decrease in the conversion of char-N to NO with an increase in char-

$413 \mathrm{~N}$ content, indicating that the reduction of the formed NO by char may be faster for high-nitrogen 414 chars. $^{8,21}$ However, the conversion of char-N to NO did not correlate with the NO reduction 415 reactivities of the chars as shown in Figure 12a. Combustion studies revealed a decreased 416 formation of $\mathrm{NO}$ and an increased formation of $\mathrm{N}_{2} \mathrm{O}$ with a higher char- $\mathrm{N}$ content at $800^{\circ} \mathrm{C}$, seen 417 in Figure 12b and c. During fixed bed combustion, the formed $\mathrm{NO}$ and $\mathrm{N}_{2} \mathrm{O}$ could either react with 418 the char from which it was produced or with other secondary char particles in the bed. To gain 419 insight into the inherent conversion of char- $\mathrm{N}$ to $\mathrm{NO}$ and $\mathrm{N}_{2} \mathrm{O}$ for a certain char particle size range, 420 combustion experiments with varying char mass were conducted. The results revealed that the 421 fractional conversion of char- $\mathrm{N}$ to $\mathrm{N}_{2} \mathrm{O}$ increased with a decrease in char mass and an increase in 422 char-N content. Hence, the investigated char particles inherently formed a large fraction of $\mathrm{N}_{2} \mathrm{O}$. 423 This could to some extent explain the decreasing tendency of char-N to NO conversion with an 424 increase in char- $\mathrm{N}$, as the larger proportion of $\mathrm{N}_{2} \mathrm{O}$ from combustion of high-nitrogen biomass 425 chars is more readily reduced over char than NO. However, caution must be taken when 426 interpolating these results obtained at $800^{\circ} \mathrm{C}$ to other temperatures, as the char- $\mathrm{N}$ conversion is 427 temperature dependent. ${ }^{3}$ The importance of $\mathrm{N}_{2} \mathrm{O}$ has been shown to decrease with temperature, 428 due to higher rates of competitive reactions and $\mathrm{N}_{2} \mathrm{O}$ destruction. ${ }^{4}$ 


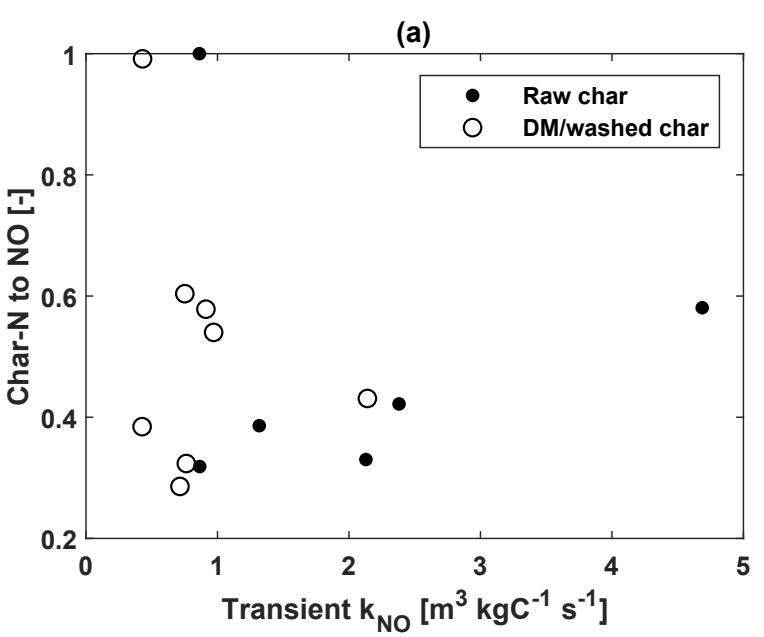

(b)
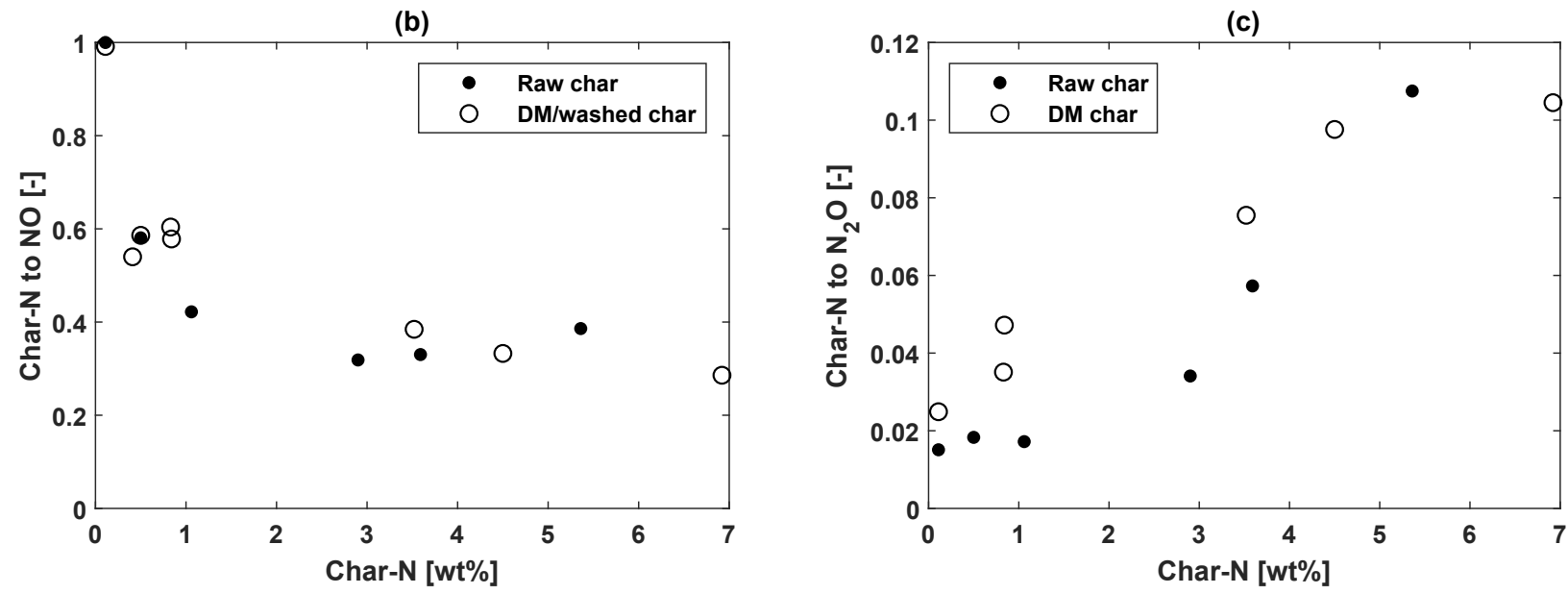

430 Figure 12. Char-N to NO conversion against the first order, transient NO reduction reactivity (a)

431 and char- $\mathrm{N}$ content (b), and char- $\mathrm{N}$ to $\mathrm{N}_{2} \mathrm{O}$ conversion against char- $\mathrm{N}$ content (c). The combustion

432 properties were determined from $20 \mathrm{mg}$ char combustion at $800^{\circ} \mathrm{C}$ in $10 \% \mathrm{O}_{2}$. The data for raw

433 pine wood char has been corrected for fluctuations in the elemental analyses, i.e., set equal to 1.

434 While the formation of $\mathrm{N}_{2} \mathrm{O}$ can partly explain the decreasing tendency of $\mathrm{NO}$ with the char- $\mathrm{N}$

435 content, additional factors could have a prominent effect. The most probable effects would be that 436 of $\mathrm{CO}$ and $\mathrm{O}_{2}$ on the $\mathrm{NO}$ reduction by $\mathrm{R} 6$ or R9, respectively. While the influence of $\mathrm{CO}$ on $\mathrm{NO}$

437 reduction in the inert NO reduction experiments was negligible due to the relatively low 438 concentration, the contribution of this in a combustion atmosphere cannot be omitted. Effluent CO 
439 concentrations were around 4000 ppmv and likely much higher near the char particle surface. The 440 local concentrations of NO in high-nitrogen chars could likewise be high, thereby increasing the 441 relative importance of R6. However, additional investigations are necessary to clarify the influence 442 of $\mathrm{R} 6$ on the overall reduction of $\mathrm{NO}$ from combustion. In the case of $\mathrm{O}_{2}$, NO reduction has 443 generally been reported to be enhanced in the presence of $\mathrm{O}_{2}$ either by oxidative active site 444 generation (R9) or activation of $(-\mathrm{CN}){ }^{57}$ Lastly, changes in surface properties and catalytic 445 components with char conversion could have an important influence on the reactivities of the 446 chars, which needs further study. 


\section{Conclusions}

448 The conversion of char-N to NO during biomass char combustion decreased with an increase in 449 the initial char-N content. As this trend did not correlate with the NO reduction reactivity of the 450 chars, an important contributing factor may be the increased formation of $\mathrm{N}_{2} \mathrm{O}$ with an increase in 451 char-N content.

452 For NO reduction over biomass char, the reactivity was largely dominated by the association 453 and content of ash forming minerals. The reactivities of chars containing a low content of 454 phosphorous (pine wood, waste wood, and straw) correlated reasonably well with the $(\mathrm{K}+\mathrm{Ca}) / \mathrm{C}$ 455 molar ratio. In comparison, the high-phosphorous (bran, DDGS, and sunflower seed) chars 456 exhibited a lower NO reduction reactivity. A plausible explanation is that the potassium in chars 457 with a high phosphorous content was bound in a catalytically less active form such as $\mathrm{KPO}_{3}$. Other 458 physical (initial surface area and porosity) and chemical (initial char-N content, and nitrogen and 459 oxygen surface functionality and content) properties did not correlate with the NO reduction 460 reactivity of the chars.

\section{$461 \quad$ Acknowledgements}

462 This project is funded by the Sino-Danish Centre for Education and Research and Technical 463 University of Denmark. In addition, the Academy of Finland financed project (289666) - fate of 464 fuel bound nitrogen in biomass gasification - is acknowledged. 


\section{$465 \quad$ References}

466 (1) Glarborg, P.; Miller, J. A.; Ruscic, B.; Klippenstein, S. J. Prog. Energy Combust. Sci. 2018, $467 \quad 67,31-68$.

468 (2) Hupa, M.; Karlström, O.; Vainio, E. Proc. Combust. Inst. 2017, 36 (1), 113-134.

469 (3) Johnsson, J. E. Fuel 1994, 73 (9), 1398-1415.

470 (4) Glarborg, P.; Jensen, A. D.; Johnsson, J. E. Prog. Energy Combust. Sci. 29 2003, 29, 89$471 \quad 113$.

472 (5) Jensen, L.; Jannerup, H.; Glarborg, P.; Jensen, A.; Dam-Johansen, K. Proc. Combust. Inst. $473 \quad 2000,28,2271-2278$.

474 (6) Zhao, K.; Glarborg, P.; Jensen, A. D. Energy \& Fuels 2013, 27, 7817-7826.

475 (7) Chambrion, P.; Kyotani, T.; Tomita, A. Energy \& Fuels 1998, 12 (2), 416-421.

476 (8) Karlström, O.; Perander, M.; DeMartini, N.; Brink, A.; Hupa, M. Fuel 2017, 190, 274-280.

477 (9) De Soete, G. G. Symp. Combust. 1991, 23 (1), 1257-1264.

478 (10) Ulusoy, B.; Wu, H.; Lin, W.; Karlström, O.; Li, S.; Song, W.; Glarborg, P.; Dam-Johansen, $479 \quad$ K. Fuel 2019, 236 (August 2018), 297-305.

480 (11) Karlström, O.; Wu, H.; Glarborg, P. Fuel 2019, 235 (August 2018), 1260-1265.

481 (12) Sørensen, C. O.; Johnsson, J. E.; Jensen, A. Energy and Fuels 2001, 15 (6), 1359-1368.

482 (13) Thomas, K. M. Fuel 1997, 76 (6), 457-473. 
483 (14) Aarna, I.; Suuberg, E. M. Fuel 1997, 76 (6), 475-491.

484 (15) Molina, A.; Eddings, E. G.; Pershing, D. W.; Sarofim, A. F. Prog. Energy Combust. Sci. $485 \quad 2000,26,507-531$.

486 (16) Dong, L.; Gao, S.; Song, W.; Xu, G. Fuel Process. Technol. 2007, 88 (7), 707-715.

487 (17) Zhong, B. J.; Tang, H. Combust. Flame 2007, 149 (1-2), 234-243.

488 (18) Wu, X.; Song, Q.; Zhao, H.; Zhang, Z.; Zhang, L.; Yao, Q. Fuel 2013, 113, 553-559.

489 (19) Zhao, Z.; Li, W.; Li, B. Fuel 2002, 81 (11-12), 1559-1564.

490 (20) Commandré, J.-M.; Stanmore, B. R.; Salvador, S. Combust. Flame 2002, 128, 211-216.

491 (21) Konttinen, J.; Kallio, S.; Hupa, M.; Winter, F. Fuel 2013, 108, 238-246.

492 (22) Molina, A.; Murphy, J. J.; Winter, F.; Haynes, B. S.; Blevins, L. G.; Shaddix, C. R. $493 \quad$ Combust. Flame 2009, $156(3)$, 574-587.

494 (23) Aho, A.; DeMartini, N.; Pranovich, A.; Krogell, J.; Kumar, N.; Eränen, K.; Holmbom, B.; 495 Salmi, T.; Hupa, M.; Murzin, D. Y. Bioresour. Technol. 2013, 128, 22-29.

496 (24) Zevenhoven, M.; Yrjas, P.; Skrifvars, B. J.; Hupa, M. Energy and Fuels 2012, 26 (10), $497 \quad 6366-6386$.

498 (25) Khazraie Shoulaifar, T.; Demartini, N.; Zevenhoven, M.; Verhoeff, F.; Kiel, J.; Hupa, M. $499 \quad$ Energy and Fuels 2013, 27 (10), 5684-5690.

500 (26) Benson, S. A.; Holm, P. L. Ind. Eng. Chem. Prod. Res. Dev. Chem. Prod. Res. Dev 1985, 2 $501 \quad$ (1), 145-149. 
502 (27) Tchoffor, P. A.; Moradian, F.; Pettersson, A.; Davidsson, K. O.; Thunman, H. Energy and $503 \quad$ Fuels 2016, 30 (12), 10435-10442.

504 (28) Wu, S. L.; Iisa, K. Energy \& Fuels 1998, 12, 457-463.

505 (29) Levy, J. M.; Chan, L. K.; Sarofim, A. F.; Beér, J. M. Symp. Combust. 1981, 18 (1), $111-$ $506 \quad 120$.

507 (30) Guo, F.; Hecker, W. C. Symp. Combust. 1996, 26, 2251-2257.

508 (31) Guo, F.; Hecker, W. C. Symp. Combust. 1998, 27 (2), 3085-3092.

509 (32) Schönenbeck, C.; Gadiou, R.; Schwartz, D. Fuel 2004, 83 (4-5), 443-450.

510 (33) Garijo, E. G.; Jensen, A. D.; Glarborg, P. Energy \& Fuels 2003, 17, 1429-1436.

511 (34) Garijo, E. G.; Jensen, A. D.; Glarborg, P. Combust. Flame 2004, 136 (1-2), 249-253.

512 (35) Kapteijn, F.; Moulijn, J. A.; Matzner, S.; Boehm, H. 1999, 37, 1143-1150.

513 (36) Ninomiya, Y.; Yokoi, K.; Arai, N.; Hasatani, M. Int. Chem. Eng. 1989, 29 (3), 512-516.

514 (37) Winter, F.; Löffler, G.; Wartha, C.; Hofbauer, H.; Preto, F.; Anthony, E. J. Can. J. Chem. $515 \quad$ Eng. 1999, 77, 275-283.

516 (38) Molina, A.; Sarofim, A. F.; Ren, W.; Lu, J.; Yue, G.; Beér, J. M.; Haynes, B. S. Combust. $517 \quad$ Sci. Technol. 2002, $174(11-12), 43-71$.

518 (39) Feng, B.; Liu, H.; Yuan, J.; Lin, Z.; Liu, D.; Leckner, B. Energy \& Fuels 1996, No. 10, $519 \quad 203-208$.

520 (40) López, D.; Calo, J. Fuel 2007, 86, 1900-1907. 
521 (41) Johnsson, J. E.; Jensen, A. Proc. Combust. Inst. 2000, 28, 2353-2359.

522 (42) Karlström, O.; Brink, A.; Hupa, M. Energy \& Fuels 2013, 27, 1410-1418.

523 (43) Hayhurst, A. N.; Lawrence, A. D. Prog. Energy Combust. Sci. 1992, 18, 529-552.

524 (44) Dong, L.; Gao, S.; Song, W.; Xu, G. Fuel Process. Technol. 2007, 88 (7), 707-715.

525 (45) Guerrero, M.; Millera, Á.; Alzueta, M. U.; Bilbao, R. Energy \& Fuels 2011, 25, 1024-1033.

526 (46) Wu, X. Y.; Song, Q.; Zhao, H. B.; Zhang, Z. H.; Yao, Q. Environ. Sci. Technol. 2014, 48

527 (7), 4184-4190.

528 (47) Pevida, C.; Arenillas, A.; Rubiera, F.; Pis, J. J. Fuel 2005, 84 (17), 2275-2279.

529 (48) Chambrion, P.; Orikasa, H.; Suzuki, T.; Kyotani, T.; Tomita, A. Fuel 1997, 76 (6), $493-$ 530498.

531 (49) Pels, J. R.; Kapteijn, F.; Moulijn, J. A.; Zhu, Q.; Thomas, K. M. Carbon N. Y. 1995, 33 (11), $532 \quad 1641-1653$.

533 (50) Xu, J.; Sun, R.; Ismail, T. M.; Sun, S.; Wang, Z. Energy and Fuels 2017, 31 (12), 13406$534 \quad 13415$.

535 (51) Phiri, Z.; Everson, R. C.; Neomagus, H. W. J. P.; Wood, B. J. J. Anal. Appl. Pyrolysis 2017, $536 \quad 125$ (July 2016), 127-135.

537 (52) Stańczyk, K. Energy and Fuels 1999, 13 (1), 82-87.

538 (53) Stańczyk, K. Energy and Fuels 2004, 18 (2), 405-409.

539 (54) Darvell, L. I.; Brindley, C.; Baxter, X. C.; Jones, J. M.; Williams, A. Energy and Fuels 
$540 \quad$ 2012, $26(11), 6482-6491$.

541 (55) Liu, X.; Luo, Z.; Yu, C. Fuel 2019, 242 (September 2018), 389-397.

542 (56) Wu, H.; Castro, M.; Jensen, P. A.; Frandsen, F. J.; Glarborg, P.; Dam-Johansen, K.; Røkke, $543 \quad$ M.; Lundtorp, K. Energy and Fuels 2011, 25 (7), 2874-2886.

544 (57) Chambrion, P.; Kyotani, T.; Tomita, A. Symp. Combust. 1998, 27, 3053-3059. 